\title{
A HISTÓRIA DA QUÍMICA POR MEIO DOS “ARES”: UMA CONTRIBUIÇÃO EXPERIMENTAL DIRECIONADA AO ENSINO DE QUÍMICA
}

\author{
THE HISTORY OF CHEMISTRY THROUGH THE "AIRS": AN \\ EXPERIMENTAL CONTRIBUTION TO CHEMISTRY TEACHING
}

\author{
Suelen dos Santos Silva ${ }^{1}$ \\ Paula Marcelly Alves Machado ${ }^{2}$ \\ Wagner da Silva Terra ${ }^{3}$
}

\begin{abstract}
Resumo: O Ensino de Química no Brasil nos dias atuais segue, predominantemente, um modelo tradicional, sendo verificada a utilização de metodologias pedagógicas repetitivas de baixo potencial de aprendizagem. Nesse contexto o presente trabalho teve por intuito elaborar um plano de aula diferenciado que envolvesse conteúdos químicos, dados históricos e discussões filosóficas a partir do tema "Ares", utilizando a demonstração investigativa como recurso didático para propiciar uma maior motivação e envolvimento dos discentes. Para se alcançar o objetivo proposto, foi realizado um conjunto de quatro experimentos, utilizando materiais de baixo custo e fácil aquisição, a saber: Peso do flogisto; Síntese do Ar Fixo $\left(\mathrm{CO}_{2}\right)$; Síntese do Ar Inflamável $\left(\mathrm{H}_{2}\right)$; Síntese do Ar Desflogisticado $\left(\mathrm{O}_{2}\right)$. A análise qualitativa dos dados obtidos demonstrou que o formato de aula utilizado é aplicável ao Ensino Médio, tornando a aula mais dinâmica, sendo, portanto, apreciada pela maior parte dos discentes, o que possibilitou uma maior motivação desses.
\end{abstract}

Palavras-chave: Experimentação Demonstrativa; História da Química; Recursos no Ensino de Química.

\begin{abstract}
The Chemistry teaching in Brazil nowadays follows, predominantly, a traditional model, being verified the use of repetitive pedagogical methodologies with low learning potential. In this context, the present work aimed to elaborate a different lesson plan involving chemical contents, historical data and philosophical discussions based on the theme "Airs", using investigative demonstration as a didactic resource to provide more motivation and involvement of students. To achieve the proposed goal, a set of four experiments was carried out, using low-cost and easy-to-acquire materials, namely: Weight of phlogiston; Synthesis of Fixed Air $\left(\mathrm{CO}_{2}\right)$; Flammable Air Synthesis $\left(\mathrm{H}_{2}\right)$; Synthesis of Dephlogisticated Air $\left(\mathrm{O}_{2}\right)$. The qualitative analysis of the data obtained showed that the class format used is applicable to high school, making the class more dynamic, being, therefore, appreciated by most of the students, which enabling a greater motivation.
\end{abstract}

Keywords: Demonstrative Experimentation; History of Chemistry; Chemistry Teaching Resources.

\footnotetext{
${ }^{1}$ Licenciada em Química pelo Instituto Federal Fluminense (IFFluminense) campus Cabo Frio, Cabo Frio, Rio de Janeiro, Brasil. E-mail: suelen.silsantos@gmail.com.

${ }^{2}$ Doutora em Química pela Universidade Federal do Rio de Janeiro (UFRJ). Professora do Instituto Federal Fluminense (IFFluminense) campus Cabo Frio, Cabo Frio, Rio de Janeiro, Brasil. E-mail: p_marcelly@hotmail.com.

${ }^{3}$ Doutor em Ciências Naturais pela Universidade Estadual do Norte Fluminense Darcy Ribeiro (UENF). Professor do Instituto Federal Fluminense (IFFluminense) campus Campos Centro, Campos dos Goytacazes, Rio de Janeiro, Brasil. E-mail: wterra@iff.edu.br.
} 
A partir das vivências em sala de aula e dos resultados apresentados por diferentes trabalhos na área de Ensino de Química, verifica-se que a abordagem dessa Ciência no Ensino Médio, no Brasil, ainda segue, predominantemente, um modelo tradicional (PAZINATO; BRAIBANTE, 2014; MARCELINO; LINHARES; OLIVEIRA, 2013; BERTON, 2015: BARROS et al., 2016; SILVA et al., 2019; SOUZA et al., 2020). Nesse formato, o professor é considerado o detentor de todo o saber, sendo, portanto, o agente ativo do processo de ensino e aprendizagem. Enquanto isso, o aluno é o sujeito passivo desse processo, considerado somente como receptor do conhecimento "pronto e acabado" fornecido pelo docente (NICOLA; PANIZ, 2016). Em grande parte das vezes, a utilização desse modelo se apresenta assim como proposto por Comenius e Locke no século XVII, no qual o aluno é como uma folha em branco a ser preenchida pelas informações apresentadas pelo professor. Nesse modelo as abordagens práticas e históricas e as experiências anteriormente vividas pelo aluno não são consideradas, o que, consequentemente, dificulta o processo de ensino e aprendizagem (NICOLAY, 2011; PEREIRA, 2011).

Assim como nas demais áreas do conhecimento, o modelo de ensino tradicionalista no Ensino de Ciências Naturais valoriza a memorização de diferentes conceitos e métodos. A partir desses, é exigido dos alunos a confecção de reações, processos, entre outros aspectos científicos, na maior parte das vezes, por meio de avaliações fechadas e tradicionais (SANTOS; SCHNETZLER, 2014; COSTA et al., 2005; BENEDETTI-FILHO et al., 2019). Além disso, nesse método de ensino normalmente não são apresentados aos discentes os meios que deram origem as leis trabalhadas em sala de aula. Esse fato acaba por gerar uma aceitação por parte dos discentes, o que pode resultar em uma redução do caráter crítico dos educandos (SANTOS; SCHNETZLER, 2014).

No método tradicionalista os conhecimentos são apresentados como verdades incontestáveis, sendo a memorização dos conceitos, leis e enunciados e a formulação matemática privilegiadas no processo de ensino e aprendizagem (OLIVEIRA 2010a; BENETTI-FILHO et al., 2019). Portanto, esse método abandona as discussões que possibilitam as descobertas da Ciência e suas consequentes aplicações na sociedade em que vivemos (BENETTI-FILHO et al., 2019). 


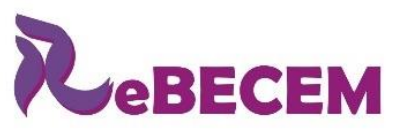

\section{Revista Brasileira de Educação em \\ Ciências e Educação Matemática}

DOI: https://doi.org/10.33238/ReBECEM.2020.v.4.n.4.25344

De modo geral a utilização de metodologias tradicionais dificulta a compreensão dos conteúdos ministrados, gerando desinteresse e desmotivação entre os discentes, o que resulta em um distanciamento entre professores e alunos, promovendo, muitas vezes, relações mecânicas e ritualistas (CABRAL; CARVALHO; RAMOS, 2004; COSTA et al., 2005; SILVA et al., 2019). Portanto, as diferentes estratégias tradicionais de ensino apresentam baixo potencial de aprendizagem, fazendo com que o discente aprenda mecanicamente um determinado conteúdo, que por sua vez, tende a permanecer por menos tempo na estrutura cognitiva dos educandos, principalmente devido ao caráter literal e arbitrário dessa aprendizagem (AUSUBEL; NOVAK; HANESIAN., 1978; MOREIRA, 2011; BRAATHEN, 2012).

Uma forma de minimizar esse distanciamento é a utilização de recursos educacionais adequados, que possibilitem uma compreensão efetiva do que é ensinado em sala de aula, visto que contribuem para a aprendizagem e a motivação dos discentes (SILVA et al., 2019; NICOLA; PANIZ, 2016). Nesse sentido, Nicola e Paniz destacam que: "quando o recurso utilizado demonstra resultados positivos, o aluno torna-se mais confiante, capaz de se interessar por novas situações de aprendizagem e de construir conhecimentos mais complexos" (NICOLA; PANIZ, 2016, p. 357).

Portanto, quando utilizado adequadamente, um recurso pedagógico se torna um poderoso instrumento para promover a aprendizagem do aluno, visto que, recursos educacionais possibilitam uma melhor aplicação do conteúdo, permitindo que o discente aprenda de forma mais efetiva e dinâmica (SOUZA, 2007). Apesar disso, muitos educadores são resistentes a utilização de recursos educacionais em suas aulas (NICOLA; PANIZ, 2016). Esse fato se deve à diferentes fatores, tais como: medo do novo, ausência de tempo para planejamento das atividades e facilidade em se utilizar a mesma metodologia em todas as turmas, ano após ano. No entanto, outros fatores externos ligados ao sistema educacional são determinantes para influenciar a processo de inserção de recursos pedagógicos com maior potencial de aprendizagem. Mesmo assim, medidas inovadoras vêm surgindo nas últimas décadas, com intuito de possibilitar uma melhor relação entre professor, aluno e conhecimento. Dentre essas medidas, três merecem destaque no Ensino de Química, assim como destaca Lisbôa (2015):

\footnotetext{
A experimentação é um dos principais alicerces que sustentam a complexa rede conceitual que estrutura o Ensino de Química. Ele não é o único, uma vez que se encontra entrelaçado com outros, como o construído pela História da Química e o construído pelo contexto sociocultural de que o estudante faz parte (LISBÔA, 2015, p. 198).
} 
DOI: https://doi.org/10.33238/ReBECEM.2020.v.4.n.4.25344

A experimentação no Ensino de Química é um recurso de grande importância, principalmente devido as especificidades que essa área de conhecimento possui. Dentre elas, as que mais se destacam são: a natureza experimental da Química, seu grande caráter abstrato e a necessidade de uma linguagem específica, repleta de símbolos e equações. Essas especificidades são provenientes dos três níveis de abordagem dessa Ciência, que juntos possibilitam a construção do conhecimento químico, a saber: o fenomenológico, o teórico e o representacional (MACHADO, 2004; OLIVEIRA, 2010b). O primeiro deles está relacionado ao concreto, ou seja, aos conhecimentos que podem ser vistos, sendo perceptível a inclusão da experimentação e das vivências químicas dos educandos nesse tipo de abordagem (OLIVEIRA, 2010b). As atividades experimentais devem sempre ser vinculadas à segunda forma de abordagem, a teórica, para que assim, a aula experimental não seja simplesmente executar um roteiro. Portanto, a teoria e a prática devem estar associadas de tal modo que a aprendizagem do discente seja alcançada (ROSITO, 2003; FURMAN, 2009). Essa abordagem, segundo Machado (2004) “[...] relaciona-se a informações de natureza atômico-molecular, envolvendo, portanto, explicações baseadas em modelos abstratos" (MORTIMER; MACHADO; RAMANELLI, 2000, p. 276). Por fim, a abordagem representacional engloba “[...] as ferramentas simbólicas empregadas para representar a relação entre teoria e fenômeno" (OLIVEIRA, 2010b, p. 26).

Neste contexto, uma abordagem experimental resulta em um ambiente propício para especulações e construções/reconstruções de ideias, permitindo assim, o desenvolvimento de competências e habilidades necessárias para que se alcance o conhecimento químico. Esses processos, associados às atividades em grupo, são apresentados por diferentes autores como excelentes métodos para aumentar o interesse dos discentes (BAZIN, 1987; FREIRE, 1996; ROSITO, 2003; OLIVEIRA, 2010b). Sendo assim, a experimentação se evidencia como uma estratégia didática que propicia a criação de problemas contextualizados, permitindo que os discentes realizem questionamentos investigativos e estimulem suas criticidades, além de possibilitar o aprimoramento de habilidades e competências fundamentais para uma vida em sociedade (GUIMARÃES, 2009: OLIVEIRA, 2010b).

Esses pressupostos estão de acordo com a teoria socio-histórica de Vygotsky, a qual preconiza que:

O desenvolvimento das funções psíquicas dos seres humanos ocorre a partir da atividade prática, nas relações que os seres humanos estabelecem em si e, com 
DOI: https://doi.org/10.33238/ReBECEM.2020.v.4.n.4.25344

a natureza. É partilhando das relações de trabalho, participando ativamente na coletividade, que o indivíduo apropria-se da linguagem, dos instrumentos físicos produzidos historicamente, do conhecimento acumulado pelas gerações precedentes e culturalmente disponíveis (THOFEHRN; LEOPARDI, 2006, p. 696).

Segundo a perspectiva vygotskiana, a zona de desenvolvimento proximal (ZDP) é um domínio psicológico em permanente transformação, sendo os aspectos afetivo e intelectual indissociáveis e não opositores entre si. Assim, de acordo com essa teoria a motivação se apresenta como um fator que favorece o processo de ensino e aprendizagem (OLIVEIRA, 2010b).

Apesar de várias teorias educacionais apresentarem dados que direcionem para abordagens experimentais no Ensino de Ciências, fatores como os encargos dos educadores muito além do satisfatório, a ausência de materiais e instalações adequados, o elevado número de alunos por classe e o extenso conteúdo programático são alguns dos fatores abordados por Laburú, Barros e Kanbach (2007) que dificultam a realização de experimentos em sala de aula.

Apesar disso, Oliveira (2010c) relata que diferentes abordagens experimentais podem ser realizadas para que alguns dos problemas apresentados anteriormente sejam minimizados. Segundo a autora, os experimentos podem ser demonstrativos, descritivos (verificação) ou investigativos. Apesar de no primeiro caso, o professor ter um papel mais ativo, esse tipo de abordagem possibilita que os alunos observem o nível fenomenológico, relatam e discutam sobre as teorias inerentes aos processos e, por fim, consigam representar, por meio de símbolos, desenhos, esquemas, entre outros, o que foi observado e discutido. Oliveira (2010c) e Araújo e Abib (2003) também destacam que a experimentação demonstrativa pode ser uma alternativa eficiente quando se possui recursos escassos de tempo e materiais. Além de se apresentar como uma alternativa aplicável para turmas numerosas e/ou espaços inapropriados para que todos os alunos participem da experimentação. Contudo, de acordo com Carvalho (2019, p. 13), demonstrações investigativas podem ser realizadas principalmente quando "a aparelhagem oferece perigo ao ser manipulada pelos alunos". Nesse modelo experimetal os alunos resolvem a problemática estipulada pelo professor e podem contribuir com a manipulação dos experimentos, indicando como o professor deve proceder nas atividades a serem realizadas.

As atividades de verificação e investigação são mais abertas do que as demonstrativas, sendo, portanto, melhor desenvolvidas com alunos que já possuem um 
DOI: https://doi.org/10.33238/ReBECEM.2020.v.4.n.4.25344

certo grau de experiência experimental. Essas abordagens se diferem principalmente quanto aos papéis dos professores e alunos, cabendo aos docentes, no caso dos experimentos de verificação, fiscalizar, diagnosticar e corrigir as atividades dos alunos, e, nos experimentos de investigação, orientar e incentivar os questionamentos e decisões tomadas pelos discentes. Em contrapartida, no primeiro tipo de abordagem, o aluno é responsável por executar o experimento e formular explicações para os fenômenos observados, enquanto que, no segundo tipo, o aluno deve participar ativamente de todas as etapas de elaboração do experimento: pesquisa, planejamento, execução e discussão da atividade (OLIVEIRA, 2010c).

\begin{abstract}
Nesse sentido, é necessário que o professor conheça e analise essa diversidade de possibilidades para que possa focalizar suas ações naquelas que lhe pareçam mais coerentes com o tipo de experimento, com a turma, com os recursos, o espaço e o tempo que tem disponível para realizá-las, ou ainda de acordo com os saberes que pretende desenvolver na aula (OLIVEIRA, 2010c, p. 152).
\end{abstract}

Pesquisadores da área de Ensino de Química apontam que, além da experimentação, a implementação de dados históricos pode minimizar o distanciamento entre os alunos e os aspectos químicos da Ciência (MATHEWS, 1990; MARTORANO; MARCONDES 2012; BELTRAN, 2013; ILHA; ADAIME, 2020; CHAMIZO; GARCÍA, 2020). Segundo esses autores, a inclusão da História da Ciência no Ensino de Química possibilita que o aluno tenha um olhar diferenciado para determinado conteúdo, possibilitando que o educando "enxergue" a Química com outros olhos. Ou seja, possibilita que o discente visualize a Química como uma Ciência não estática, mutável e repleta de discussões históricas e experimentais. Além disso, a utilização de recursos históricos no Ensino de Química possibilita novas reflexões sobre a construção do conhecimento científico, sendo perceptível o caráter transitório da Ciência, uma vez que “a Ciência não está pronta e acabada" (MELO; LUCA, 2020, p. 17).

De acordo com Oki e Moradillo (2008), a inserção de uma maior quantidade de conhecimentos de História, Filosofia e Sociologia da Ciência nos currículos dos diferentes níveis de ensino pode contribuir positivamente para o processo de ensino e aprendizagem dos discentes. Segundo os autores, a humanização do ensino científico é uma das principais vantagens dessa inserção, possibilitando que esses apresentem novas concepções sobre a Ciência, de forma mais relativa e contextualizada e menos simplista. Oki e Moradillo (2008) também destacam que a História da Ciência é indispensável para o enriquecimento cultural, permitindo a conexão entre a Ciência e a sociedade. Essa afirmação se baseia nos argumentos relatados por Beltran, Saito e Trindade (2014) que 


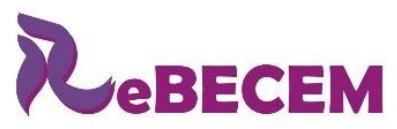

\section{Revista Brasileira de Educação em \\ Ciências e Educação Matemática}

DOI: https://doi.org/10.33238/ReBECEM.2020.v.4.n.4.25344

destacam que a Ciência é fruto de "raciocínios que se desenvolvem dentro de um contexto social", com intuito de atender as demandas apresentadas pela humanidade (LIMA; SILVA, 2020, p. 159).

Apesar de pesquisadores destacarem a importância da História da Química como mediadora para a aprendizagem dos discentes, a inserção desses temas em currículos ainda segue modelos tradicionais de ensino (OKI; MORADILLO, 2008). Ou seja, durante as aulas, os alunos são informados sobre fatos históricos, frequentemente isolados, de forma desarticulada com o conteúdo, descontextualizados com a realidade dos discentes e sem que haja uma construção histórica-reflexiva sobre o conteúdo ministrado. Ou seja, apesar da apresentação dos marcos históricos propiciarem determinada motivação nos discentes, a utilização desse recurso articulado aos aspectos filosóficos da Ciência permite a reflexão e discussão do conteúdo, possibilitando que o aprendizado seja alcançado com maior eficiência. Sendo assim, um grande desafio no Ensino de Química é a inserção de fatos históricos relacionados a discussões filosóficas sobre a Ciência nas disciplinas de nível médio, de tal modo, que o conteúdo seja ministrado e que o aluno aprenda de uma forma social, interdisciplinar e contextualizada.

Nesse contexto, lança-se o seguinte questionamento: seria possível realizar uma aula direcionada à introdução de Química no Ensino Médio de forma articulada aos dados históricos e discussões filosóficas por meio de demonstrações experimentais investigativas?

Com intuito de solucionar a referida problemática, o presente trabalho teve por objetivo elaborar um plano de aula que envolvesse conteúdos químicos, dados históricos e discussões filosóficas a partir do tema "Ares", utilizando a experimentação demonstrativa como recurso didático para propiciar uma aprendizagem mais efetiva aos discentes. Para se alcançar o objetivo proposto os alunos do primeiro ano do curso Técnico em Petróleo e Gás integrado ao Ensino Médio do Instituto Federal Fluminense campus Cabo Frio tiveram acesso a um conjunto de quatro experimentos demonstrativos relacionados ao tema proposto. Durante a aula partiu-se dos tempos mais longínquos, desde quando os filósofos determinavam os conceitos da matéria, até os dias atuais, de forma que fosse possível relacionar conteúdos químicos, dados históricos e discussões de como os cientistas produzem e refutam suas teorias. 


\section{Metodologia}

\subsection{Tipologia da Pesquisa}

O conhecimento científico não é universal, estático e imutável, mas sim, um compilado de informações, que quanto mais observações, nas mais variáveis condições possíveis, maior será a confiabilidade das generalizações realizadas (CHALMERS, 1993; PASCHOARELLI; MEDOLA; BONFIM, 2015; SILVEIRA, 1989). Sendo assim, o presente trabalho se apresenta como mais uma dessas observações, sendo possível realizar um relato de experiência sobre a aplicação de dados históricos e discussões filosóficas a partir do tema "Ares", utilizando a experimentação demonstrativa como recurso didático.

Como a pesquisa desenvolvida nesse trabalho não teve por objetivo realizar medições dos eventos estudados e nem realizar análises estatísticas para resolução de uma dada problemática, ela se classifica como uma análise qualitativa (PASCHOARELLI; MEDOLA; BONFIM, 2015). Neste trabalho, realizou-se uma análise descritiva dos dados, sendo esses obtidos por meio do contato direto e interativo entre os pesquisadores e o momento em se que deu o objeto de estudo, buscando averiguar o entendimento dos fenômenos por meio da perspectiva dos alunos envolvidos (NEVES, 1996).

\subsection{Público-alvo e Lócus da Pesquisa}

O presente trabalho teve como público-alvo alunos de uma turma vespertina do primeiro ano do curso Técnico em Petróleo e Gás integrado ao Ensino Médio do Instituto Federal Fluminense campus Cabo Frio, totalizando 33 discentes atingidos com a proposta dessa pesquisa. A intervenção se deu na segunda semana de aula da referida turma, sendo utilizado três tempos de 50 min para realização das atividades propostas.

Na primeira semana de aula, os alunos realizaram o processo de ambientação nas instalações do instituto, conheceram seus novos professores, seus colegas de classe e, além disso, tiveram contato com as particularidades de cada disciplina. Ou seja, antes da intervenção os alunos só possuíam os conhecimentos químicos que adquiriram em outras instituições de ensino, sendo, portanto, o momento propício para iniciar a construção e reflexão do conhecimento químico-hitórico-filosófico da matéria. 


\subsection{Elaboração e Aplicação dos Experimentos}

A primeira etapa dessa pesquisa envolveu a escolha de um tema norteador que possibilitasse a inserção de dados históricos relacionados aos conteúdos e conhecimentos específicos da Química. Além disso, a escolha do tema central foi realizada com intuito de promover discussões filosóficas a respeito de como a Ciência é mutável e dependente das concepções históricas. Após várias reflexões, o tema escolhido foi “Ares”, sendo esse um dos elementos que norteiam a Teoria dos Quatro Elementos. Porém, optou-se por colocar o tema no plural, justamente para deixar claro que mais de um componente na fase gasosa seria abordado durante as aulas experimentais.

Após a escolha do tema central realizou-se uma série de testes com a finalidade de selecionar os experimentos mais adequados e suas correspondentes metodologias de aplicação. Nessa etapa foi possível selecionar quatro experimentos direcionados ao tema "Ares", sendo eles: 1) Peso do Flogisto; 2) Síntese do Ar Fixo; 3) Síntese do Ar Inflamável; 4) Síntese do Ar Desflogisticado. Apesar da utilização de materiais alternativos na confecção dos experimentos, optou-se por uma experimentação demonstrativa, justamente por se tratar de experimentos que envolvam fogo e gases perigosos, como os gases oxigênio e hidrogênio. Porém foram criadas problemáticas a serem resolvidas pelos discentes em todos os experimentos, com intuito de possibilitar um caráter investigativo na experimentação realizada, caracterizando-se como uma demonstração investigativa, de acordo com Carvalho (2019).

Os experimentos foram realizados de forma a simular as ideias dos pensadores da época, porém utilizando materiais e reagentes contemporâneos. Além disso, os experimentos foram realizados em ordem cronológica dos descobrimentos dos gases, sendo possível correlacionar os conceitos históricos com conceitos químicos, a fim de proporcionar uma maior motivação dos discentes.

No início da aula foram apresentadas aos discentes as principais correntes filosóficas que deram origem a Teoria dos Quatro Elementos. Ou seja, nessa primeira etapa foram apresentadas as ideias centrais de Tales de Mileto, Anaxímenes e Heráclito, em que cada filósofo defendia um "elemento" como sendo o fundamental para criação de todas as coisas. Para Tales, a água correspondia a esse elemento, enquanto que para Anaxímenes e Heráclito era o ar e o fogo, respectivamente. Em seguida foi apresentado aos discentes que a combinação dessas teorias por Empédocles resultou em uma nova proposta, conhecida como a Teoria dos Quatro Elementos, sendo essa indicada por alguns 


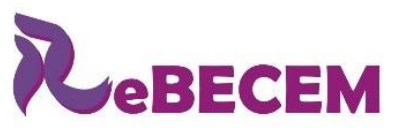

\section{Revista Brasileira de Educação em \\ Ciências e Educação Matemática}

DOI: https://doi.org/10.33238/ReBECEM.2020.v.4.n.4.25344

pesquisadores como o início do pensamento científico que apresentava ideias químicas (STRATHERN, 2002). Portanto, nessa etapa os alunos foram levados a se colocarem nos lugares dos filósofos e cientistas da época, com intuído de apresentar aos discentes os caminhos que originaram os conceitos da matéria, os quais serão imprescindíveis para a construção do conhecimento químico na estrutura cognitiva dos discentes.

Após apresentação dos conhecimentos filosóficos que deram origem a Teoria dos Quatro Elementos, os alunos foram questionados, de forma oral, como eles poderiam comprovar ou refutar a concepção filosófica da matéria apresentada até então. Após averiguar as respostas, novos fatos históricos foram apresentados aos discentes, sendo destacado o misticismo e uma atuação mais prática, características essas que estavam presentes na época dos Alquimistas. No entanto, foi deixado claro ao discentes que, apesar da característica prática observada na época dos alquimistas, a concepção dos quatro elementos, idealizada pelos filósofos, ainda permaneceu durante muitos anos como sendo a teoria mais aceita (STRATHERN, 2002).

Em seguida, foi apresentado aos discentes que a Teoria dos Quatro Elementos perdurou até Johann Becher, um perito alemão, que introduziu na segunda metade do século XVII uma nova ideia sobre a constituição da matéria. De acordo com essa nova teoria a matéria seria constituída por ar, água e terra, dividindo a última em: Terra Vitrificável (sal); Terra Mercurial (mercúrio) e Terra Combustível (enxofre = terra pinguis) (STRATHERN, 2002; PRADO; CARNEIRO, 2018). Além disso, foi apresentado aos discentes que as ideias de Becher foram ampliadas por Georg Stahl, o que proporcionou uma nova concepção para a terra pinguis, que a partir de então foi nomeada de flogisto (STRATHERN, 2002).

Partindo dessas informações, os alunos foram questionados sobre como eles poderiam confirmar ou refutar a teoria do flogisto, utilizamdo como materiais de partida, itens básicos presentes no cotidiano deles, como por exemplo papel e palha de aço. Após as indicações dos alunos, verificou-se que a experimentação seria uma alternativa viável para esse processo. Sendo assim, os alunos sugeriram que os diferentes materiais disponíveis fossem queimados com intuinto de verificar as alterações de massa. Por esse motivo utilizou-se uma balança semi-analítica para averiguar as alterações de massa após a combustão nos materiais disponíveis. Destaca-se que, apesar dos reagentes e materiais serem de fácil aquisição e baixo custo, a utilização desses equipamentos foi primordial para constatação ou refutação da teoria do flogisto. A baixa dispobilidade desses equipamentos também direciona a aplicação desse experimento para uma demonstração 


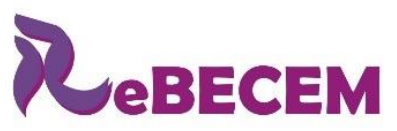

\section{Revista Brasileira de Educação em \\ Ciências e Educação Matemática}

DOI: https://doi.org/10.33238/ReBECEM.2020.v.4.n.4.25344

investigativa. A descrição dos procedimentos realizados pelos alunos para o experimento "Peso do Flogisto" é apresentada no Quadro 1 e demonstrado na Figura 1.

\section{Experimento 1: Peso do Flogisto}

Nesse experimento utilizou-se duas balanças semi-analíticas, duas cápsulas de porcelana, dois isqueiros, $3 \mathrm{~g}$ de papel picado e $3 \mathrm{~g}$ de palha de aço.

$\mathrm{Na}$ balança 1, pesou-se no interior da cápsula de porcelana aproximadamente $3 \mathrm{~g}$ de papel em pequenos pedaços. Em seguida, retirou-se a cápsula de porcelana sem que a balança fosse zerada e o papel foi levando à combustão utilizando cuidadosamente o isqueiro. Ao final da combustão, pesou-se o material novamente e os discentes verificaram a redução da massa do papel após a queima.

Realizou-se o mesmo procedimento anterior, substituindo o papel picado por aproximadamente $3 \mathrm{~g}$ de palha de aço, porém nesse experimento, os alunos observaram que a massa do conjunto cápsula de porcelana e palha de aço aumentou.

As diferenças de massa foram discutidas entre os alunos baseando-se no contexto histórico da teoria do flogisto.

\section{Quadro 1: Descrição do Experimento "Peso do Flogisto"}

Fonte: Elaboração própria
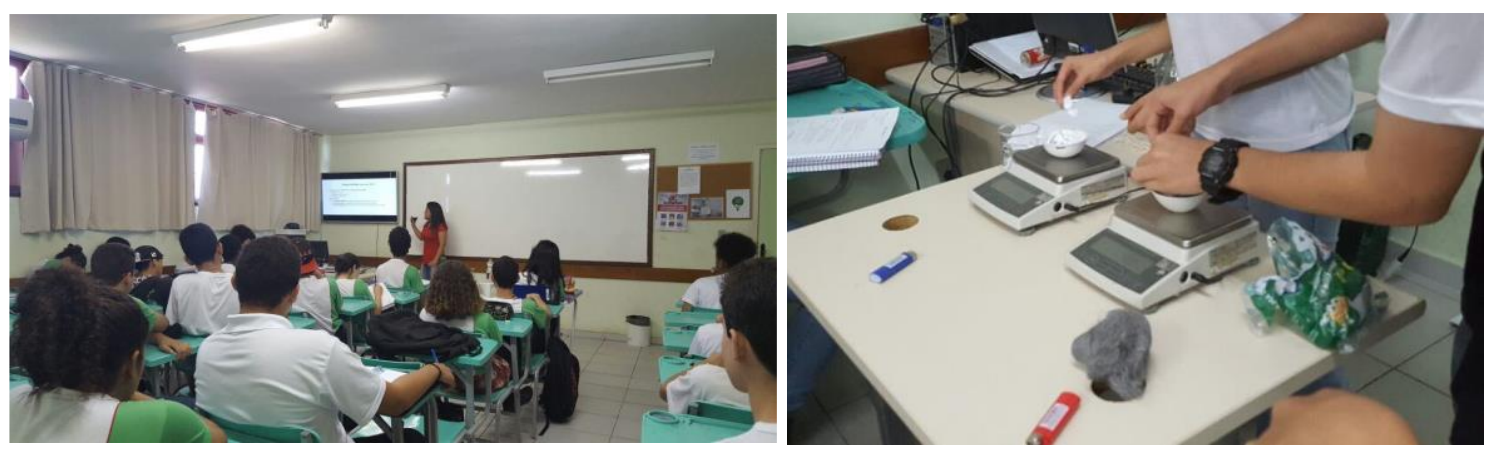

Figura 1: Apresentação da parte inicial do relato de experiência [esquerda] e realização do experimento "Peso do Flogisto" [direita]

Fonte: Elaboração própria

Após discussão química e filosófica sobre o experimento realizado, continuou-se o relato histórico direcionado a produção dos "ares". Foi apresentado aos discentes os processos que impulsionaram a teoria do flogisto. Novamente a experimentação foi utilizada como forma de validar, mesmo que equivocadamente, a teoria elaborada. Diante disso, foi apresentado aos alunos os resultados obtidos por três grandes cientistas da época: Joseph Black, Joseph Priestley e Henry Cavendisch, os quais tinham por intuito confirmar, alterar ou refutar as afirmações realizadas por essa teoria.

Com base nos resultados obtidos por Joseph Black, Joseph Priestley, Henry Cavendisch e pelos alunos foi possível apresentar aos discentes que determinado material, após entrar em contato com outras substâncias ou processos, como aquecimento, poderia originar diferentes substâncias, inclusive algumas gasosas.

Nesse primeiro momento foi apresentado aos discentes os resultados obtidos por Joseph Black, que verificou a produção de um ar após a magnésia alba reagir com ácidos ou ser aquecida a determinada temperatura. Sendo assim, os discentes tomaram 


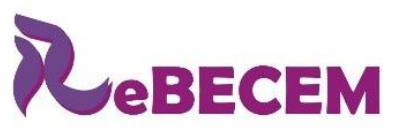

\section{Revista Brasileira de Educação em \\ Ciências e Educação Matemática \\ ISSN 2594-9179}

DOI: https://doi.org/10.33238/ReBECEM.2020.v.4.n.4.25344

conhecimento que Black denominou esse gás de Ar Fixo, visto que ele parecia estar "fixado" em alguns materiais, como por exemplo os alcalis brandos, tais como os carbonatos de sódio e potássio. Também foi explicado aos discentes que o Ar Fixo apresentava outra propriedade, a de ser reabsorvido pelo sólido gerado, resultando, novamente, nos alcalis brando utilizado. Ou seja, o Ar Fixo era "refixado" no material sólido, de tal modo, que esse novo gás pudesse participar de processos químicos (GORRI; SANTIN-FILHO, 2009).

A discussão desses dados históricos impulsionou a realização, de forma demonstrativa, porém com a participação de alguns discentes, do segundo experimento, o qual foi intitulado de Síntese do Ar Fixo, sendo esse apresentado no Quadro 2 e, posteriormente, ilustrado na Figura 2. Nesse experimento os alunos foram questionados sobre qual gás seria formado, ou seja, o Ar Fixo corresponderia a qual substância presente em nosso cotidiano. Para isso os alunos tiveram que testar uma das propriedades do gás formado, a saber a inflamabilidade. Essa sugestão partiu de um discente que correlacionou os extintores de incêncio do tipo $\mathrm{CO}_{2}$ com o gás formado.

\section{Experimento 2: Síntese do Ar Fixo}

Para a síntese do Ar Fixo partiu-se de um princípio similar ao idealizado por Joseh Black.

Em um erlermeyer de $250 \mathrm{~mL}$ adicionou-se aproximadamente duas colheres de bicarbonato de sódio. Em seguida, adicionou-se uma quantidade de vinagre até que todo o sal fosse coberto pelo líquido adicionado. Imediatamente após a adição do bicarbonato, colocou-se um vidro de relógio na parte superior do erlenmeyer e aguardaram-se alguns minutos.

Logo após, foi inserida uma haste metálica, com uma vela acessa na extremidade inferior, dentro do recipiente onde o gás havia sido produzido. Sendo observado que a vela se apagava instantaneamente.

\section{Quadro 2: Descrição do Experimento Síntese do Ar Fixo}

Fonte: Elaboração própria
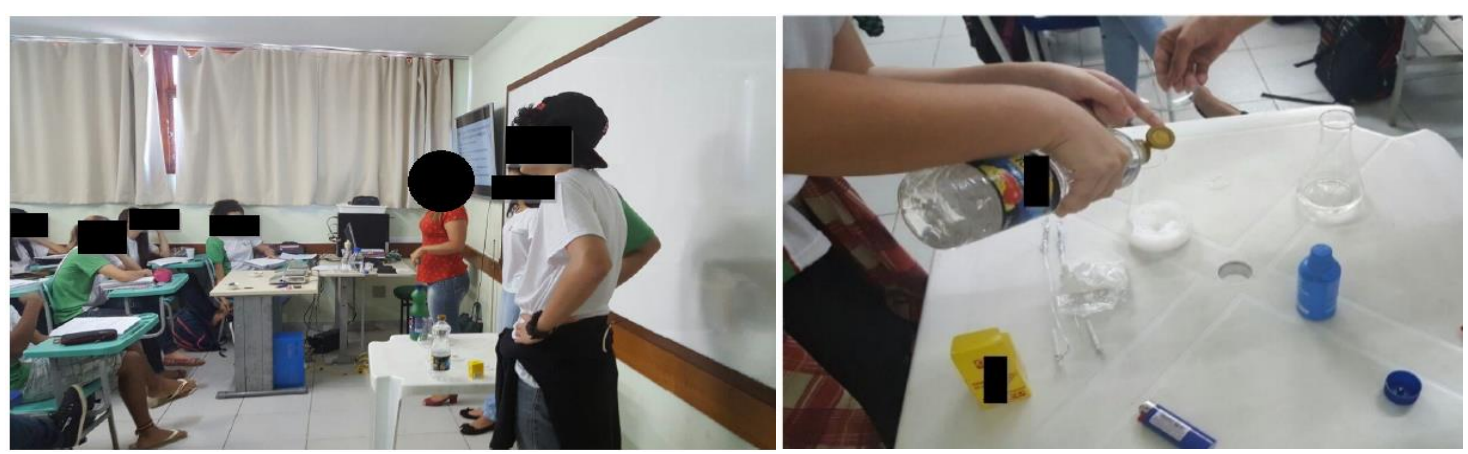

Figura 2: Apresentação da realização do experimento "Síntese do Ar Fixo"

Fonte: Elaboração própria

Após realização e discussão dos princípios químicos inerentes à síntese do $\mathrm{Ar}$ Fixo, foi apresentado aos alunos que Henry Cavendisch observou que certos ácidos ao reagirem com metais liberavam um gás, que ao ser aproximado de uma chama iniciava 
DOI: https://doi.org/10.33238/ReBECEM.2020.v.4.n.4.25344

um processo de combustão, que tinha como produto a água. De acordo com esses dados, os discentes tomaram conhecimento que Cavendisch nomeou o gás obtido de $\mathrm{Ar}$ Inflamável, justamente devido à sua inflamabilidade (STRATHERN, 2002; BRITO, 2008; LEVADA et al., 2010). Após a apresentação desses relatos históricos, os alunos foram questionados sobre o que a experimentação realizada por Cavendisch influenciou na Teoria dos Quatro Elementos, podendo confirmá-la, modificá-la ou refutá-la. Antes da experimentação os discentes não conseguiram chegar a nenhuma conclusão definitiva. Mesmo sendo apresentado aos discentes que as características de inflamabilidade e leveza do ar sintetizado impulsionaram a teoria do flogisto, fazendo com que Cavendisch se equivocasse em concluir que havia isolado o flogisto (STRATHERN, 2002).

Para que os alunos pudessem experimentar algumas das sensações que Henry Cavendisch experimentou foi realizado um terceiro experimento, intitulado: Síntese do Ar Inflamável. Esse procedimento também foi realizado de forma demonstrativa com apoio de outros discentes, que apresentavam as suas sugestões para obtenção dos resultados e análises dos dados obtidos (Figura 3). O procedimento realizado é apresentado no Quadro 3, sendo possível verificar que a formação de grande quantidade de gás imflamável tornou o experimento mais perigoso que os demais, sendo a atuação do professor ainda mais presente nessa etapa.

\section{Experimento 3: Síntese do Ar Inflamável}

Para a síntese do Ar Inflamável partiu-se de um princípio similar ao idealizado por Cavendisch, sendo substituída a solução ácida por uma solução aquosa de hidróxido de sódio.

Para realização do procedimento utilizou-se um kitassato com uma bexiga fixada na saída lateral da vidraria. Em seguida, adicionou-se aproximadamente uma folha e meia de papel alumínio picado em aproximadamente $50 \mathrm{~mL}$ de uma solução de soda cáustica presente no interior do kitassato. Após adição do material metálico o recipiente foi devidamente fechado e aguardou-se o tempo necessário para a que a bexiga fosse preenchida.

Para verificar as propriedades do gás produzido inicialmente a bexiga foi completamente fechada com auxílio de um barbante, sendo possível verificar se o gás obtido era mais ou menos denso que o ar atmosférico. Em seguida, acendeu-se uma vela com bastante cuidado em uma região da sala de aula distante da bexiga. Após esse procedimento a bexiga foi aprisionada em uma haste longa e aproximada com bastante cuidado de uma vela acessa com intuito de verificar a inflamabilidade do gás produzido.

Quadro 3: Descrição do Experimento Síntese do Ar Inflamável

Fonte: Elaboração própria 


\section{$R_{\text {eBECEM }}$}
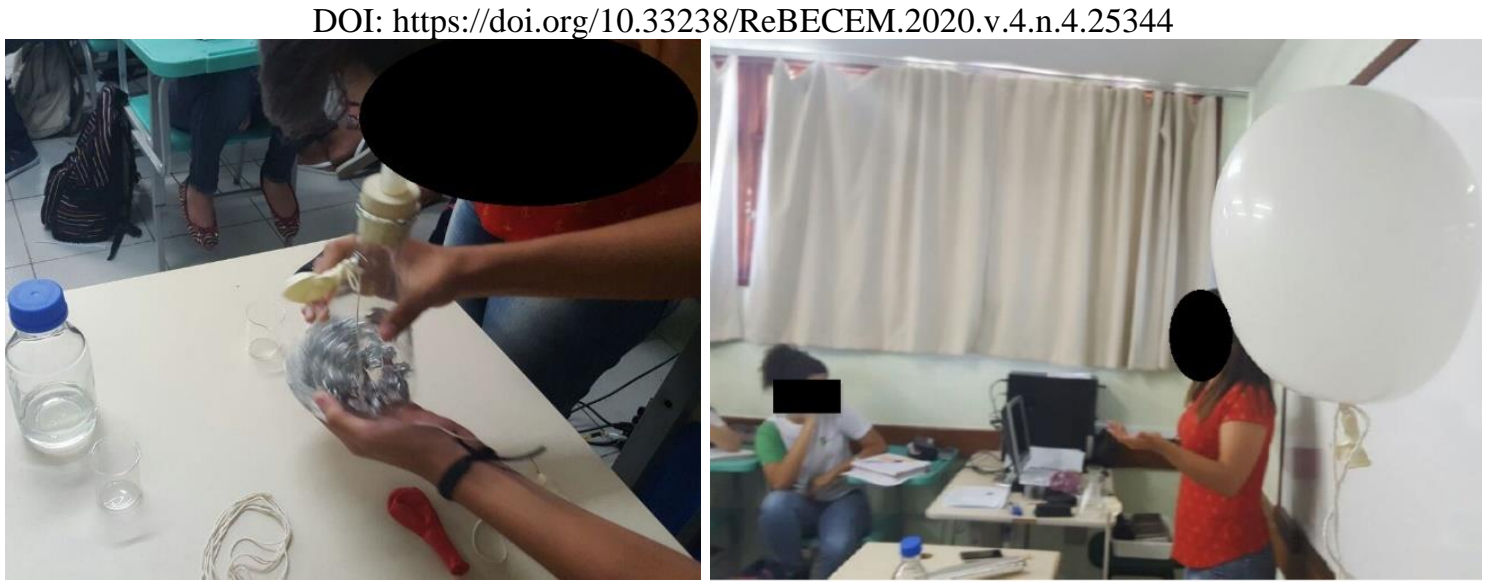

Figura 3: Apresentação da realização do experimento "Síntese do Ar Inflamável"

Fonte: Elaboração própria

Após realização do experimento e indicação pelos alunos que o gás inflamável corresponderia ao gás hidrogênio, os discentes concluiram que a síntese desse gás refutaria a ideia dos quatro elementos básicos, justamente pela mólecula de água ser um produto da combustão, não podendo ser considerada um elemento básico.

Por fim, foram apresentadas aos discentes as contribuições realizadas por Joseph Priestley para diferentes substâncias gasosas, sendo dado maior destaque para o gás intitulado por ele como Ar Desflogisticado. Durante a aula foi apresentado aos discentes que Priestley produziu um ar com características diferentes dos demais gases sintetizados, ressaltando que a produção desse se deu pelo aquecimento do óxido de mercúrio, denominado na época de mercurius precipitatus per se (GORRI; SANTIN-FILHO, 2009). Como foi destacado em aula que o referido gás, além da respirabilidade e solubilidade em água, tinha como propriedade a capacidade de sustentar a chama de uma vela, os discentes sugeriram refazer o segundo experimento, sendo substituído o Ar Fixo pelo Ar Desflogisticado, como apresentado no Quadro 4 e na Figura 4.

\section{Experimento 4: Síntese do Ar Desflogisticado}

Para a síntese do Ar Desflogisticado partiu-se de um procedimento bastante diferente do realizado por Joseh Priestley, justamente devido à toxicidade do óxido de mercúrio e da facilidade em se obter materiais alternativos. Sendo assim, optou-se por utilizar reagentes de fácil aquisição e baixa toxicidade.

Em um erlermeyer de $250 \mathrm{~mL}$ adicionou-se quantidades equivalentes de água sanitária e água oxigenada 10 volumes. Em seguida, imediatamente após a adição das substâncias, colocou-se um vidro de relógio na parte superior do erlenmeyer e aguardaram-se alguns minutos.

Logo após, foi inserida uma haste metálica, com uma vela acessa na extremidade inferior, dentro do recipiente onde o gás havia sido produzido. Sendo observado que a vela ficava instantaneamente com a chama ainda mais intensa.

Quadro 4: Descrição do Experimento Síntese do Ar Desflogisticado

Fonte: Elaboração própria 
DOI: https://doi.org/10.33238/ReBECEM.2020.v.4.n.4.25344
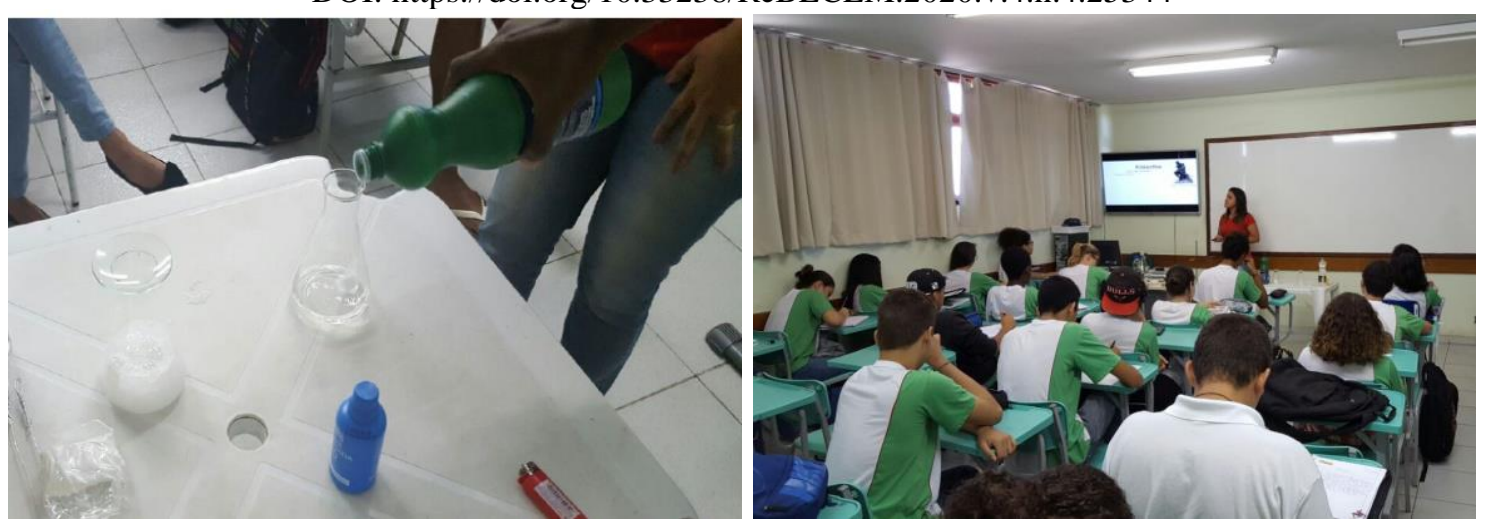

Figura 4: Apresentação da realização do experimento "Síntese do Ar Desflogisticado" [esquerda] e momento de discussão e apresentação dos resultados [direita]

Fonte: Elaboração própria

Após realização de cada experimento, foram privilegiadas abordagens que relacionavam conteúdos de Química com fatos históricos, sempre que possível fazendo uma relação filosófica. Esse tipo de abordagem foi utilizado com objetivo de apresentar aos discentes os caminhos que deram origem a algumas teorias bastante disseminadas na Química atual, deixando claro para os discentes que essa Ciência não é estática e imutável, mas sim, é uma construção científico-histórica.

\subsection{Instrumentos de Coleta de Dados}

A coleta de dados para esse relato de experiência se deu de duas formas distintas. A primeira foi obtida pelas percepções dos pesquisadores responsáveis pela aplicação dessa proposta, na qual observou-se o comportamento dos discentes, principalmente sobre a motivação e participação durante a realização da intervenção históricoexperimental. A segunda forma se deu por meio de um questionário de caráter qualitativo (Quadro 5). O referido instrumento de coleta de dados foi aplicado antes e após a intervenção, sendo a única diferença entre os questionários a presença de uma questão aberta presente no questionário final, a qual solicitava aos discentes que relatassem suas percepções sobre a aula que acabaram de presenciar. Cabe ressaltar, que os alunos não assinaram ou se identificaram nos questionários respondidos, promovendo anonimidade aos dados obtidos.

Os questionários utilizados possibilitaram reunir e analisar as informações obtidas antes e após a aplicação da proposta. Essa forma de avaliação, segundo Rampazzo (2009), é uma forma rápida e eficaz de avaliar e coletar dados e informações do entrevistado. 


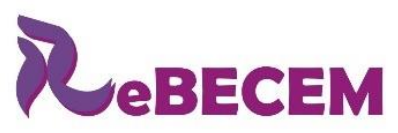

\section{Revista Brasileira de Educação em \\ Ciências e Educação Matemática \\ ISSN 2594-9179}

DOI: https://doi.org/10.33238/ReBECEM.2020.v.4.n.4.25344

Prezado(a) aluno(a), gostaríamos muito de contar com sua participação nesse trabalho. Sendo assim, solicitamos que você responda ao seguinte questionário, que tem por intuito analisar a intervenção histórico-experimental realizada por meio dessa pesquisa.

Desde já agradecemos a sua participação e gostaríamos de destacar que não será necessária a identificação nesse instrumento de coleta de dados.

\begin{tabular}{|c|c|}
\hline N. ${ }^{\circ}$ & Questão \\
\hline 1 & $\begin{array}{l}\text { Como ocorreu a construção da Química como Ciência? } \\
\text { ( ) Sempre foi Química } \\
\text { ( ) As Ciências, de modo geral, são o amadurecimento e aperfeiçoamento do conhecimento } \\
\text { filosófico } \\
\text { ( ) Foi desenvolvida pelos portugueses e chegou ao Brasil na época do descobrimento }\end{array}$ \\
\hline 2 & $\begin{array}{l}\text { O que essa figura representa para o Ensino de Química? } \\
\text { ( ) um triângulo CCC } \\
\text { ( ) princípios básicos para a reação de combustão } \\
\text { ( ) princípios básicos para formação do flogisto }\end{array}$ \\
\hline 3 & $\begin{array}{l}\text { Qual a reação entre o ácido acético }\left(\mathrm{CH}_{3} \mathrm{COOH}\right) \text { e o bicarbonato de sódio }\left(\mathrm{NaHCO}_{3}\right) \text { ? } \\
\begin{array}{l}\text { ( ) } \mathrm{NaHCO}_{3}(\mathrm{~s})+\mathrm{CH}_{3} \mathrm{COOH}(\mathrm{aq}) \rightarrow \mathrm{CH}_{3} \mathrm{COONa}(\mathrm{aq})+\mathrm{H}_{2} \mathrm{O}(\mathrm{l})+\mathrm{CO}_{2}(\mathrm{~g}) \\
\left(\text { ) } \mathrm{NaHCO}_{3}(\mathrm{~s})+\mathrm{CH}_{3} \mathrm{COOH}(\mathrm{aq}) \rightarrow \mathrm{NaHCO}_{3}(\mathrm{~s})+\mathrm{H}_{2} \mathrm{O}(\mathrm{l})\right. \\
\left(\text { ) } \mathrm{NaHCO}_{3}(\mathrm{~s})+\mathrm{CH}_{3} \mathrm{COOH}(\mathrm{aq}) \rightarrow \mathrm{CH}_{3} \mathrm{COONa}(\mathrm{aq})+\mathrm{CO}(\mathrm{g})\right.\end{array}\end{array}$ \\
\hline 4 & $\begin{array}{l}\text { A combustão do gás hidrogênio forma? } \\
\begin{array}{lll}\text { ( ) } \mathrm{H}_{2} & \left(\text { ( ) } \mathrm{H}_{2} \mathrm{O}\right. & \left(\text { ) } \mathrm{O}_{2}\right.\end{array}\end{array}$ \\
\hline 5 & $\begin{array}{l}\text { O que significa a palavra “ar" ou “ares” para a História da Química? } \\
\text { ( ) um estado físico da matéria } \\
\text { ( ) o gás carbônico } \\
\text { ( ) uma identidade dada aos compostos ou elementos no estado gasoso }\end{array}$ \\
\hline 6 & $\begin{array}{l}\text { O que foi o flogisto? } \\
\text { ( ) o fogo } \\
\text { ( ) um elemento químico } \\
\text { ( ) matéria inanimado que o combustível possuía e junto ao ar facilitava a queima }\end{array}$ \\
\hline 7 & $\begin{array}{l}\text { A água }\left(\mathrm{H}_{2} \mathrm{O}\right) \text { é: } \\
\begin{array}{lll}(\mathrm{)}) \text { um átomo } & (\mathrm{)}) \text { uma substância simples } & (\mathrm{)}) \text { uma substância composta }\end{array}\end{array}$ \\
\hline 8 & 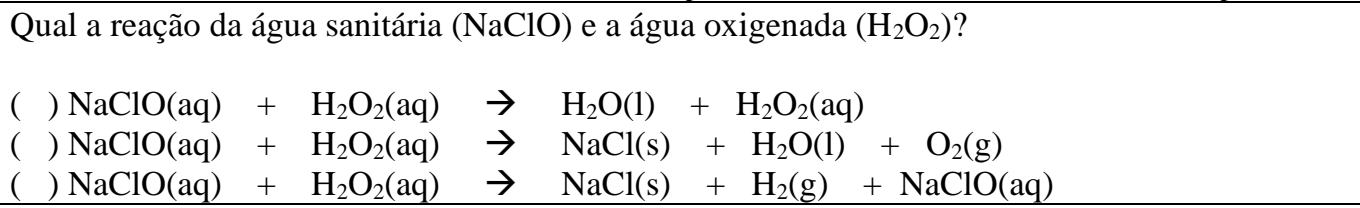 \\
\hline 9 & $\begin{array}{l}\text { Uma combustão completa em material orgânico é caracterizada por: } \\
\text { ( ) a formação de água e gás oxigênio } \\
\text { ( ) a formação de água e gás carbônico } \\
\text { ( ) a formação de água e gás monóxido de carbono }\end{array}$ \\
\hline 10 & $\begin{array}{l}\text { A matéria no estado gasoso apesenta uma única característica. } \\
\text { ( ) verdadeiro, sendo assim todo gás é igual } \\
\text { ( ) falso, pois a matéria tem características de acordo com sua composição fundamental } \\
\text { ( ) verdadeiro, pois todo gás possui maior agitação molecular }\end{array}$ \\
\hline 11 & $\begin{array}{l}\text { Do que tudo é feito? } \\
(\mathrm{l}) \text { de } 4 \text { elementos fundamentais } \quad(\quad) \text { de átomos }\end{array}$ \\
\hline 12 & $\begin{array}{l}\text { Como a matéria é transformada? } \\
\begin{array}{l}\text { ( ) por meio do calor } \\
\text { ( ) por meio de uma reação química ou transformação física (energia) }\end{array}\end{array}$ \\
\hline
\end{tabular}


DOI: https://doi.org/10.33238/ReBECEM.2020.v.4.n.4.25344

\begin{tabular}{|c|l|}
\hline 13 & $\begin{array}{l}\text { Por que a massa do ferro aumenta quando ele oxida? } \\
\text { ( ) pois é um metal } \\
\text { ( ) pois ele deixa de ser ferro (Fe) e passa a ser óxido de ferro }(\mathrm{FeO}) \text {, absorve calor } \\
\text { ( ) pois ele deixa de ser ferro (Fe) e passa a ser óxido de ferro (FeO), absorve oxigênio do ar }\end{array}$ \\
\hline 14 & $\begin{array}{l}\text { É possível em uma única aula você aprender, História da Química, conteúdos químicos exigidos } \\
\text { pela ementa e ainda participar de atividades experimentais? }\end{array}$ \\
\hline $15^{*}$ & $\begin{array}{l}\text { ( ) sim é possível } \\
\text { ( ) um pouco é possível }\end{array}$ \\
\hline
\end{tabular}

Quadro 5: Questionário aplicado aos discentes antes e após a intervenção histórico-experimental

Fonte: Elaboração própria

*Somente presente no Questionário Final.

As questões fechadas relacionadas ao conteúdo, presentes em ambos os questionários, foram analisadas de forma comparativa, indicando o número de acertos, erros e respostas em branco, antes e após a intervenção experimental. Já a questão aberta foi analisada de acordo com a Análise de Conteúdo (AC) idealizada por Laurence Bardin (2011).

Para a referida análise iniciou-se pela leitura "flutuante" das respostas fornecidas pelos discentes, sendo utilizado todos os relatos como corpus de pesquisa, os quais foram organizados de tal modo que facilitassem a interpretação dos dados. Em seguida, o corpus de pesquisa foi desmembrado em Unidades de Significação (USs) e categorizado por similaridade de acordo com os preceitos de Bardin (2011), sendo destacada a frequência de repetição das USs. Por fim, os dados foram interpretados e relacionados ao referencial teórico.

\section{Resultados e Discussão}

\subsection{Perspectivas observadas no decorrer da aplicação do relato de experiência}

No decorrer da aplicação, foi perceptível que a maior parte dos discentes demonstrou bastante atenção tanto em relação à apresentação dos dados históricosfilosóficos como em relação aos conceitos químicos apresentados durante a aula. Acredita-se que esse fato é devido à metodologia utilizada no decorrer da intervenção, visto que a demonstração investigativa articulada à História e Filosofia da Ciência se mostrou como um recurso motivador, o que possibilitou a externalização da curiosidade dos discentes. Essa observação vai ao encontro com o relato apresentado por Franscisco- 
DOI: https://doi.org/10.33238/ReBECEM.2020.v.4.n.4.25344

Júnior e colaboradores (2008), que destacam que "o professor deve suscitar nos estudantes o espírito crítico, a curiosidade, a não aceitação do conhecimento simplesmente transferido" (FRANSCISCO-JÚNIOR; FERREIRA; HARTWIG, 2008, p. 35). Ou seja, o professor, como mediador da aprendizagem deve possibilitar a análise crítica do que é ensinado, de forma contextualizada, para que assim a curiosidade dos discentes seja estimulada. Apesar dos referidos autores direcionarem suas pesquisas para a Experimentação Problematizadora baseada nos momentos pedagógicos de Delizoicov (1983), suas observações e comparações com a Educação Bancária, conceituada e criticada por Paulo Freire (2005), vão ao encontro com os dados obtidos nesse relato de experiência. Essas observações se devem ao fato da demostração investigativa articulada a História e Filosofia da Ciência possibilitar que a curiosidade e motivação dos discentes sejam alcançadas, fazendo com que eles queiram aprender, fator esse necessário para a uma aprendizagem significativa, assim como preconiza David Ausubel (1963). Além disso, os recursos utilizados, os conteúdos químicos, os dados históricos e as discussões filosóficas realizadas durante a intervenção possibilitaram uma participação mais efetiva dos discentes, o que contrapõe a Educação Bancária.

No início da aula, após apresentação dos conhecimentos filosóficos que deram origem a Teoria dos Quatro Elementos, os alunos apresentaram inconsistências na referida teoria. Sendo assim, os alunos foram questionados como eles poderiam resolver essa problemática; comprovando, modificando ou refutando as concepções do que seria a matéria segundo os filósofos. Nesse momento, percebeu-se que a sala de aula foi unânime em indicar que a experimentação seria uma possibilidade para confirmar a teoria recém apresentada. O que deixou claro que, apesar dos alunos não conhecerem nominalmente, eles já apresentavam conceitos básicos relacionados ao método hipotético-dedutivo idealizada por Popper (1975), que segundo Diniz (2015) consiste em:

\footnotetext{
se perceber problemas, lacunas ou contradições no conhecimento prévio ou em teorias existentes. A partir desses problemas, lacunas ou contradições, são formuladas conjecturas, soluções ou hipóteses; essas, por sua vez, são testadas no que Popper chamava de técnica de falseamento (DINIZ, 2015, p. 108).
}

A constatação apresentada pelos discentes foi o ponto de partida para que eles propusessem as suas próprias hipóteses a partir dos resultados obtidos pelos experimentos demonstrativos. Que apesar de serem apresentados nesse formato - devido ao tamanho da turma, grau de periculosidade dos experimentos e do quantitativo de materiais disponíveis, como relatam Oliveira (2010b) e Araújo e Abib (2003) - foram utilizados de 
forma a gerar questionamentos. Ou seja, apesar das limitações dessa forma de experimentação a sua associação com a História e Filosofia da Ciência permitiu a realização de problemas a serem resolvidos pelos discentes, o que, de acordo com Delizoicov (1983), permite a dialogicidade com o educando, partindo "daquilo que é familiar para o aluno, pois só dessa forma ele poderá participar efetivamente desse diálogo" (DELIZOICOV, 1983, p. 86).

Outro fato que merece destaque é a pouca ou nenhuma experiência dos discentes com relação aos experimentos. Essa constatação foi coletada no decorrer da aula ministrada, estando de acordo com o perfil normalmente apresentado por alunos do primeiro ano do Ensino Médio Integrado do Instituto Federal Fluminense campus Cabo Frio. Esse resultado indica que a demonstração investigativa é uma alternativa eficiente para a inserção da experimentação para o público-alvo selecionado, pois assim, os educandos poderão ir se familiarizando com alguns aspectos desse tipo de recurso educacional, para que no futuro, abordagens experimentais mais abertas sejam utilizadas (OLIVEIRA, 2010c).

\subsection{Análise dos Questionários Diagnósticos}

Como relatado anteriormente, durante a aula, os alunos se mostraram entusiasmados, atentos e comprometidos com a atividade. Além disso, os educandos também se mostraram participativos e empenhados no preenchimento dos questionários utilizados para coleta de dados (Questionário Inicial e Final).

Por meio desses questionários foi possível compreender alguns aspectos relevantes sobre a aplicação realizada, sendo possível detectar os pontos de maior dificuldade dos discentes, bem como as suas percepções sobre a intervenção realizada.

Os resultados obtidos antes e após a intervenção realizada são apresentados na Figura 5, sendo diferenciadas, em cada uma das categorias a priori, as porcentagens de repostas corretas (C), incorretas (I) e em Branco (B). 


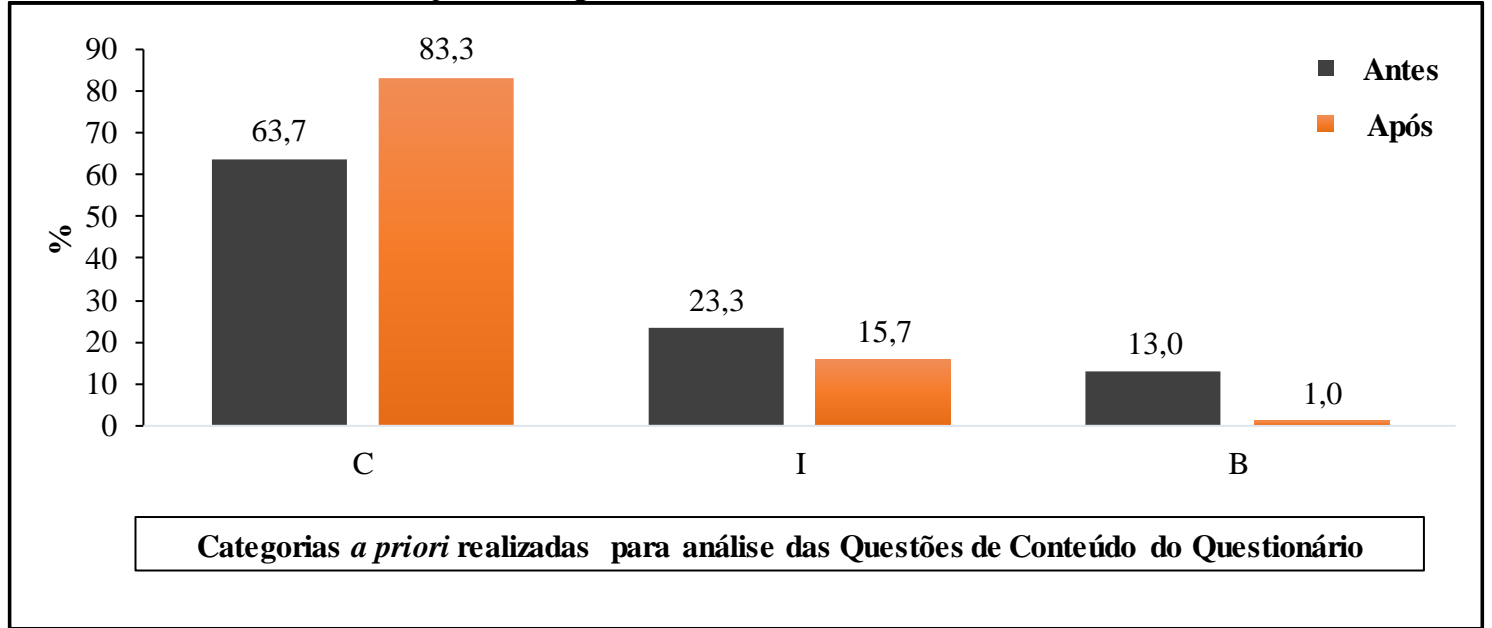

Figura 5: Resultados obtidos para os Questionários Inicial e Final antes e após a intervenção realizada nesse relato de experiência.

Fonte: Elaboração própria

Por meio dos resultados apresentados na Figura 5, verificou-se que os discentes apresentavam conhecimentos sobre esses conteúdos antes da intervenção realizada. Visto que, antes da aplicação, os discentes já apresentavam uma elevada porcentagem de acertos $(63,7 \%)$.

As questões relacionadas aos dados históricos, possivelmente, puderam ser respondidas devido alguns aspectos da História da Química serem amplamente difundidos na cultura popular. Enquanto que, as questões relacionadas à Química Básica, possivelmente, puderam ser respondidas devido ao nível escolar dos discentes. Sabe-se que os alunos do nono ano do Ensino Fundamental, normalmente, já apresentam contato com alguns aspectos básicos da Química, os quais são requeridos no processo de seleção para ingresso no instituto lócus dessa aplicação. Esses fatos sugerem que os discentes já possuíam alguns conhecimentos prévios relacionados aos conteúdos básicos de Química, favorecendo a aplicação e possibilitando uma melhor compreensão dos conteúdos relacionados aos experimentos realizados.

Apesar das porcentagens de acertos terem apresentado valores elevados antes da realização dos experimentos, foi observado um leve aumento na porcentagem desses acertos após a aplicação da abordagem Histórico-Experimental. Por meio da análise do Questionário Final foi observado que $83,3 \%$ das questões foram assinaladas corretamente. Portanto, observou-se um aumento de quase $20 \%$ no número de acertos para as questões analisadas.

Durante a análise dos questionários, foi perceptível que o formato escolhido auxiliou o processo de ensino e aprendizagem de algumas representações químicas. Sendo esse processo favorecido devido ao caráter experimental da abordagem realizada, 


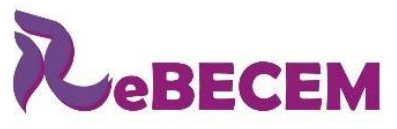

\section{Revista Brasileira de Educação em \\ Ciências e Educação Matemática}

DOI: https://doi.org/10.33238/ReBECEM.2020.v.4.n.4.25344

o qual possibilitou a construção dos três níveis de abordagens da Química, sendo estes: o fenomenológico, o teórico e o representacional (OLIVEIRA, 2010a). Acredita-se que se esses conteúdos fossem apresentados exclusivamente de forma teórica, como na maior parte das vezes para alunos do Ensino Médio, a motivação dos educandos seria comprometida, o que poderia facilmente interferir nas respostas finais apresentadas pelos alunos. Sendo assim, a abordagem experimental realizada possibilitou que os discentes compreendessem os conteúdos químicos de forma divertida, o que foi potencializado pela apresentação dos dados históricos e pelas discussões filosóficas realizadas.

Os alunos foram questionados antes e após a aplicação desse relato de experiência, se era "possível em uma única aula você aprender História da Química, conteúdos químicos exigidos pela ementa e ainda participar de atividades experimentais?" (Quadro 5). Antes da abordagem experimental, 7\% dos alunos destacaram que, "Sim"; $45 \%$ indicaram que era "Pouco" possível e 45\% destacaram que esse formato de abordagem era impossível (Figura 6). Ou seja, a maior parte dos alunos estavam pouco confiantes sobre a abordagem que iriam presenciar, possivelmente por acreditarem que aulas contendo relatos históricos e experimentos podem interferir nos conteúdos ministrados.

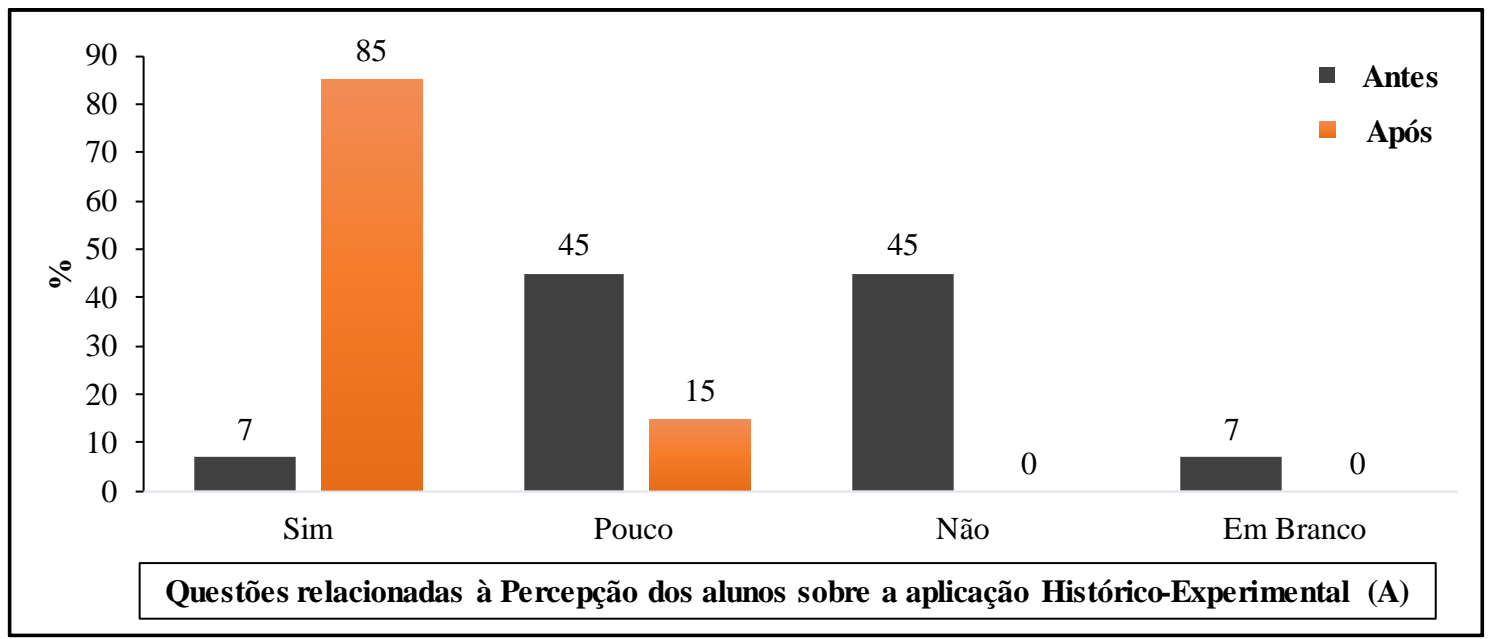

Figura 6: Resultados obtidos para os Questionários Inicial e Final antes e após a intervenção realizada nesse relato de experiência para a categoria $A\left(n_{A}=33\right)$

Fonte: Elaboração própria

A percepção dos discentes sobre a possibilidade de uma aplicação que envolvesse aspectos históricos, experimentais e químicos foi bastante alterada após a intervenção realizada. Verificou-se que, após a aula, $85 \%$ dos alunos destacaram que é possível relacionar dados de História da Química, conteúdos químicos exigidos pela ementa e ainda participar de atividades experimentais em uma aula. $\mathrm{O}$ aumento de $7 \%$ para $85 \%$ 


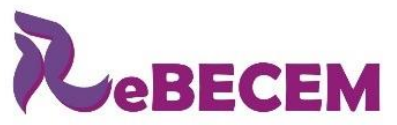

\section{Revista Brasileira de Educação em \\ Ciências e Educação Matemática \\ ISSN 2594-9179}

DOI: https://doi.org/10.33238/ReBECEM.2020.v.4.n.4.25344

demonstra que, de forma geral, os alunos aprovaram a proposta realizada, visto que eles conseguiram relacionar as diferentes abordagens realizadas.

Os relatos descritos pelos discentes para a última questão do Questionário Final possibilitou entender as perspectivas desse público com relação à abordagem realizada. (Quadro 6). Todos os 33 alunos (A1 a A33) relataram somente pontos positivos a respeito da aplicação, destacando, de forma geral, que a realização dos experimentos possibilitou a criação de problemas presentes em suas rotinas, além de deixar a aula mais divertida e motivadora. Esses resultados estão de acordo com Guimarães (2009) e Oliveira (2010a), que destacam que a experimentação, além de ser motivadora, possibilita a criação de problemas contextualizados, fundamentais para o processo de ensino e aprendizagem.

\begin{tabular}{|c|c|c|}
\hline \multicolumn{3}{|c|}{ Total de USs $=40$} \\
\hline Categorias & Exemplos de USs recortadas & Freq. $(\%)^{*}$ \\
\hline $\begin{array}{l}\text { Importância dos } \\
\text { Experimentos para a } \\
\text { aula }\end{array}$ & $\begin{array}{l}\text { "Foi uma aula muito boa, bem explicada, e os experimentos } \\
\text { facilitaram a ilustração do que estava sendo ensinado" (Aluno } \\
\text { A1). } \\
\text { "Foi uma aula bem aproveitada por minha pessoa, eu pude } \\
\text { observar os experimentos, tirar minhas conclusões e } \\
\text { comparar com a conclusão correta, pude me divertir enquanto } \\
\text { aprendia e tive várias dúvidas esclarecidas" (Aluno A20). }\end{array}$ & $25,0 \%$ \\
\hline $\begin{array}{l}\text { Importância dos } \\
\text { Relatos Históricos } \\
\text { para a aula }\end{array}$ & $\begin{array}{l}\text { "A parte histórica foi muito importante, pois assim pude } \\
\text { entender o porquê dos conteúdos". } \\
\text { "Amei conhecer um pouco mais da História da Química, me } \\
\text { senti um cientista". }\end{array}$ & $15,0 \%$ \\
\hline $\begin{array}{l}\text { Importância da } \\
\text { abordagem } \\
\text { Histórico- } \\
\text { Experimental- } \\
\text { Ivestigativa para a } \\
\quad \text { aula }\end{array}$ & $\begin{array}{l}\text { "A dinâmica da aula foi muito interessante, ao mesmo tempo } \\
\text { aprendemos os avanços históricos da Química e aprendemos } \\
\text { também os experimentos que permitiram esses avanços" } \\
\text { (Aluno A2). } \\
\text { "Foi uma aula bem dinâmica que nos fez imaginar a Química } \\
\text { como algo além da teoria, e nos informando sobre como a } \\
\text { Química surgiu" (Aluno A8). } \\
\text { "Muito interessante a proposta que, surpreendentemente, } \\
\text { alcançou seu objetivo. Ou seja, pode-se afirmar que em uma } \\
\text { aula é possível aprender a História da Química e conceitos } \\
\text { exigidos em vestibulares, etc. Fora a parte experimental, que } \\
\text { com certeza ajuda na fixação da matéria" (Aluno A14). }\end{array}$ & $50, \%$ \\
\hline $\begin{array}{l}\text { Aumento da } \\
\text { Participação } \\
\text { Discente }\end{array}$ & $\begin{array}{l}\text { "Bem legal e interativa. Gosto quando os alunos participam, } \\
\text { deixa tudo mais interessante para os que normalmente não } \\
\text { prestam atenção (Aluno A6)." } \\
\text { "E foi usada uma maneira interessante de prender a atenção } \\
\text { dos alunos no que estava sendo ensinado" (Aluno A1). }\end{array}$ & $10,0 \%$ \\
\hline
\end{tabular}

*Freq. (Frequência de repetição) $=$ (número de USs da categoria*100)/número total de USs para a questão analisada.

Quadro 6: Exemplos de Unidades de Significação recortadas das respostas fornecidas pelos discentes para a Questão 15 do Questionário Final.

Fonte: Elaboração Própria

Como é possível obserar no Quadro 6, o aluno A1 destacou que "os experimentos facilitaram a ilustração do que estava sendo ensinado", além de ser "uma maneira 


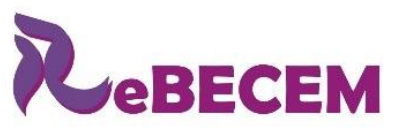

Revista Brasileira de Educação em

Ciências e Educação Matemática

DOI: https://doi.org/10.33238/ReBECEM.2020.v.4.n.4.25344

interessante de prender a atenção dos alunos". Sabe-se que atualmente um dos grandes desafios da educação é conseguir alcançar a atenção dos discentes durante as aulas, o que é extremamente necessário para o reconhecimento da informação e, consequente aprendizado (ROSA; DEPS, 2015).

Dentre as principais respostas apresentadas pelos discentes algumas estão relacionadas ao tipo de abordagem realizada (Alunos A2, A8 e A14 por exemplo). Ou seja, esses relatos destacam pontos positivos tanto em relação à parte experimental realizada como em relação à apresentação dos dados históricos utilizados, os quais foram empregados de forma associada nesse trabalho. Além da experimentação vários autores destacam que a inserção de dados históricos possibilita uma diminuição do distanciamento entre os alunos e os aspectos químicos da Ciência (OKI; MORADILLO, 2008; MARTORANO; MARCONDES 2012; ILHA; ADAIME, 2020; CHAMIZO; GARCÍA, 2020).

Apesar da experimentação realizada nesse trabalho ter uma abordagem demonstrativa é importante destacar que durante a aula, alguns alunos auxiliaram na realização dos experimentos. Esse fato possibilitou a participação um pouco mais ativa de alguns discentes durante a aula, o que consequentemente auxilia o processo de aprendizagem, assim como relatou o Aluno A6. Esse resultado está de acordo com Nascimento e Coutinho (2016) que destacam que metodologias em que os alunos possuem um potencial mais ativo possibilitam que eles utilizem "todas as suas dimensões sensório/motor, afetivo/emocional e mental/cognitiva", possibilitando uma maior aprendizagem (NASCIMENTO; COUTINHO, 2016, p. 136). Durante a aula, os alunos foram instigados a apresentarem seus pontos vista sobre os dados históricos, possibilitando a realização de uma discussão, o que também proporcionou um papel mais ativo desses discentes no decorrer da aula. Nesse sentido, ressalta-se o comentário do Aluno A20, que destacou que, por meio da aula, conseguiu tirar suas próprias conclusões e depois discutir sobre as teorias que ele havia criado, sendo possível realizar uma discussão de como as teorias são criadas, refutadas e modificadas.

Destaca-se ainda que os resultados aqui apresentados estão de acordo com alguns preceitos da teoria socio-histórica de Vygotsky, com destaque para a afirmação de que "[...] o desenvolvimento das funções psíquicas dos seres humanos ocorre a partir da atividade prática, nas relações que os seres humanos estabelecem em si e, com a natureza" (THOFEHRN; LEOPARDI, 2006, p. 696). Sendo assim, as relações presenciadas no decorrer dessa intervenção indicaram que os discentes iniciaram uma relação coletiva, 


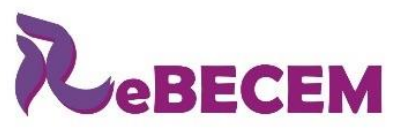

DOI: https://doi.org/10.33238/ReBECEM.2020.v.4.n.4.25344
Revista Brasileira de Educação em

Ciências e Educação Matemática

apropriando-se da linguagem da Química fundamental para o conhecimento dessa Ciência.

Por fim, alguns alunos destacaram que a aula foi bastante produtiva, possibilitando o estudo de conteúdos de Química essenciais para a sua formação. Nesse sentido a abordagem Histórico-Experimental não diminuiu a qualidade do conteúdo de Química apresentado, mas sim o aprimorou. Curiosamente, no decorrer da História das Ciências várias teorias foram refutadas a partir de novos experimentos e discussões, assim como realizado no decorrer desse relato de experiência. Dentre essas teorias destacam-se as que originaram o atual modelo atômico e a descoberta da mecânica quântica, aspectos históricos bastante importantes para várias pesquisas científicas atuais (ALVES, 1994; DE REGT, 2001; GRECCA; MOREIRA, 2001; LOPES; MACHADO, 2018).

\section{Conclusões}

Diante das informações apresentadas e discutidas anteriormente foi possível realizar um plano de aula contemplando dados históricos, discussões filosóficas, conteúdos químicos e atividades de demonstração investigativa, de forma contextualizada com a realidade sociocultural dos discentes. A realização da proposta pedagógica se deu conforme o esperado, apresentando participação ativa dos discentes, principalmente com relação às discussões realizadas no decorrer da aula. Desta forma, o presente trabalho demostrou que a utilização de uma aula múltipla no Ensino de Química, contemplando a História da Química, atividades experimentais e discussões filosóficas se torna um recurso favorável para propiciar uma aula dinâmica e com potencial motivador, trazendo um formato múltiplo, informativo e acessível ao Ensino de Química no Ensino Médio. Esses fatores são essenciais para minimizar o caráter tradicional apresentado pelo ensino dessa Ciência, possibilitando a utilização de recursos com maior potencial pedagógico, principalmente em turmas grandes em anos iniciais do Ensino Médio.

\section{Referências}


DOI: https://doi.org/10.33238/ReBECEM.2020.v.4.n.4.25344

ALVES, V. de S. Crítica da Mecânica Quântica. Revista Portuguesa de Filosofia, v. 50, n. 1-3, p. 35-50, jan./set. 1994. Disponível em: <https://www.jstor.org/stable/40337068>. Acesso em: 08 de Jul. 2020.

ARAÚJO, M. S. T; ABIB, M. L. V. S. Atividades Experimentais no Ensino de Física: diferentes enfoques, diferentes finalidades. Revista Brasileira de Ensino de Física, v. 25, n. 2, p. 176194, 2003. Disponível em: <https://www.scielo.br/pdf/rbef/v25n2/a07v25n2.pdf>. Acesso em: 08 de Jul. 2020.

AUSUBEL, D. P; NOVAK, J. D; HANESIAN, H. Educational psychology: a cognitive view. $2^{a}$ ed. Holt: Rinehart \& Winston, 1978.

AUSUBEL, D.P. The psychology of meaningful verbal learning. New York: Grune and Stratton, 1963.

BARDIN, L. Análise de Conteúdo. São Paulo, SP: Edições 70, 2011.

BARROS, E. E. S. CUNHA, J. O. S.; OLIVEIRA, P. M.; CAVALCANTE, J. W. P.; ARAUJO, M. C. R.; PEDROSA, R. E. N. B.; ANJOS, J. A. L. Atividade lúdica no ensino de química: "trilhando a geometria molecular". In: ENCONTRO NACIONAL DE ENSINO DE QUÍMICA, 18., 2016, Florianópolis. Anais... Florianópolis, SC: UFSC. p. 1-7, 2016.

BAZIN, M. Three years of living science in Rio de Janeiro: learning from experience. Scientific Literacy Papers, p. 67-74, 1987.

BELTRAN, M. H. R. História da Química e Ensino: estabelecendo interfaces entre campos interdisciplinares. Abakós, Belo Horizonte, MG, v. 1, n. 2, p. 67-77, maio 2013. Disponível em: $<$ http://periodicos.pucminas.br/index.php/abakos/article/download/P.23169451.2013v1n2p67/5324>. Acesso em: 08 de Jul. 2020.

BELTRAN, M. H. R.; SAITO, F.; TRINDADE, L. S. P. História da ciência para formação de professores. São Paulo, SP: Livraria da Física, 2014.

BENEDETTI-FILHO, E.; SANTOS, C. G. P.; CAVAGIS, A. D. M.; BENEDETTI, L. P. dos S. Desenvolvimento e aplicação de um jogo virtual no ensino de Química. Informática na Educação: teoria \& prática, Porto Alegre, RS, v. 22, n. 3, p. 144-157, set./dez. 2019. Disponível em: <https://www.seer.ufrgs.br/InfEducTeoriaPratica/article/view/90736/55723>. Acesso em: 08 de Jul. 2020.

BERTON, A. N. B. A didática no Ensino de Química. In: XII CONGRESSO NACIONAL DE EDUCAÇÃO, 2015, Curitiba, PR. Anais do XII Congresso Nacional de Educação Formação de Professores, Complexidade e Trabalho Docente, Curitiba, PR: 2015. p. 2655126559. 
DOI: https://doi.org/10.33238/ReBECEM.2020.v.4.n.4.25344

BRAATHEN, P. C. Aprendizagem Mecânica e Aprendizagem Significativa no Processo de Ensino-Aprendizagem de Química. Revista Eixo, Brasília, DF, v. 1, n. 1, p. 74-86, 2012. Disponível em: <http://revistaeixo.ifb.edu.br/index.php/RevistaEixo/article/view/53/17 >. Acesso em: 12 de nov. 2020.

BRITO, A. A. de S. "Flogisto", "calórico" \& "éter". Ciência \& Tecnologia dos Materiais, Lisboa, v. 20, n. 3-4, p. 51-63, 2008. Disponível em: <http://www.scielo.mec.pt/pdf/ctm/v20n34/v20n3-4a08.pdf>. Acesso em: 08 de Jul. 2020.

CABRAL, F. M. S.; CARVALHO, M. A. V.; RAMOS, R. M. Dificuldades no relacionamento professor/aluno: um desafio a superar. Paidéia, Ribeirão Preto, SP, v. 14, n. 29, p. 327-335, set./dec. 2004. Disponível em: <https://www.redalyc.org/pdf/3054/305425355008.pdf>. Acesso em: 08 de Jul. 2020.

CARVALHO, A. M. P. (Org.). Ensino de Ciências por Investigação - Condições para Implementação em sala de aula. São Paulo, SP: Cengage Learning, 2019.

CHALMERS, A. F. O que é ciência, afinal? São Paulo, SP: Brasiliense; 1993.

CHAMIZO, J. A.; GARCÍA, J. C. Una experiencia en la formación de docentes a partir de la historia y la filosofía de la química. Revista Eureka sobre Enseñanza y Divulgación de las Ciencias, Cádiz, v. 17, n. 1, 2020. Disponível em:

$<$ http://www.joseantoniochamizo.com/pdf/educacion/articulos/033_Experiencia_formacion_doc entes_historia_filosofia_quimica.pdf>. Acesso em: 08 de Jul. 2020.

COSTA, T. S.; ORNELAS, D. L.; GUIMARÃES, P. I. C; MERÇON, F. Corrosão na abordagem da cinética química. Química Nova na Escola, São Paulo, SP, n. 22, nov. 2005. Disponível em: <http://qnesc.sbq.org.br/online/qnesc22/a06.pdf〉. Acesso em: 08 de Jul. 2020.

DE REGT, H. W. Spacetime Visualisation and the Intelligibility of Physical Theories. Studies in History and Philosophy of Science Part B: Studies in History and Philosophy of Modern Physics, v. 32, n. 2, p. 243-265, 2001. Disponível em: <https://doi.org/10.1016/S1355-

2198(01)00007-7>. Acesso em: 08 de Jul. 2020.

DELIZOICOV, D. Ensino de Física e a concepção freiriana de educação. Revista de Ensino de Física, v. 5, n. 2, p. 85-98, 1983. Disponível em:

<http://www.sbfisica.org.br/rbef/pdf/vol05a19.pdf>. Acesso em: 08 de Jul. 2020.

DINIZ, M. T. M. Contribuições ao ensino do método hipotético-dedutivo a estudantes de Geografia. Geografia Ensino \& Pesquisa, v. 19, n. 2, p. 107-111, jan/abr. 2015. Disponível em: <https://doi.org/10.5902/2236499412995>. Acesso em: 08 de Jul. 2020.

FRANSCISCO-JÚNIOR, W.; FERREIRA, L. H., HARTWIG, R. Experimentação Problematizadora: Fundamentos Teóricos e Práticos para a Aplicação em Salas de Aula de 
DOI: https://doi.org/10.33238/ReBECEM.2020.v.4.n.4.25344

Ciências. Química Nova na Escola, n. 30, p. 34-41, nov. 2008. Disponível em:

<http://qnesc.sbq.org.br/online/qnesc30/07-PEQ-4708.pdf〉. Acesso em: 08 de Jul. 2020.

FREIRE, P. Pedagogia da Autonomia: saberes necessários à prática educativa. São Paulo, SP: Paz e Terra, 1996.

FREIRE, P. Pedagogia do oprimido. 43ª ed. Rio de Janeiro, RJ: Paz e Terra, 2005.

FURMAN, M. O ensino de ciências no ensino fundamental: colocando as pedras fundacionais do pensamento científico. São Paulo, SP: Sangari Brasil, 2009.

GORRI, A. P.; SANTIN-FILHO, O. Representação de Temas Científicos em Pintura do Século XVIII: Um Estudo Interdisciplinar entre Química, História e Arte. Química Nova na Escola, v. 31, n. 3, p. 184-189, ago. 2009. Disponível em: <http://qnesc.sbq.org.br/online/qnesc31_3/06HQ-0808.pdf>. Acesso em: 08 de Jul. 2020.

GRECA, I. M.; MOREIRA, M. A. Uma Revisão da Literatura sobre Estudos Relativos ao Ensino da Mecânica Quântica Introdutória. Investigações em Ensino de Ciências, v. 6, n. 1, p. 29-56, 2001. Disponível em:

<https://lume.ufrgs.br/bitstream/handle/10183/141218/000348941.pdf?sequence=1\&isAllowed $=\mathrm{y}>$. Acesso em: 08 de Jul. 2020.

GUIMARÃES, C. C. Experimentação no Ensino de Química: Caminhos e Descaminhos Rumo à Aprendizagem Significativa. Química Nova na Escola, São Paulo, SP, v. 31, n. 3, p. 198-202, ago. 2009. Disponível em:

<http://webeduc.mec.gov.br/portaldoprofessor/quimica/sbq/QNEsc31_3/08-RSA-4107.pdf>. Acesso em: 08 de Jul. 2020.

ILHA, G. C.; ADAIME, M. B. History and philosophy of science in chemical teaching: what's in circulation? Research, Society and Development, v. 9, n. 1, p. 1-24, 2020.

LABURÚ, C. E.; BARROS, M. A.; KANBACH, B. G. A Relação com o Saber Profissional do Professor de Física e o Fracasso da Implementação de Atividades Experimentais no Ensino Médio. Investigações em Ensino de Ciências, Porto Alegre, RS, v. 12, n. 3, p. 305-320, 2007. Disponível em: <https://www.if.ufrgs.br/cref/ojs/index.php/ienci/article/view/462/266>. Acesso em: 08 de Jul. 2020.

LEVADA, C. L.; MACETI, H.; LAUTENSCHLEGUER, I. J.; LEVADA, M. M. O. Tributo pelo Bicentenário da Morte de Henry Cavendish. Caderno de Física da UEFS, Feira de Santana, BA, v. 8, n. 1-2, p. 69-74, 2010. Disponível em:

<http://dfisweb.uefs.br/caderno/vol8n12/a3CelsoCavendish.pdf>. Acesso em: 08 de Jul. 2020.

LIMA, C. M. C.; SILVA, J. L. de P. B. Contribuições do Desenvolvimento Histórico-Cultural dos Conceitos de Ácido e de Base para o Ensino de Química. Revista Brasileira De Pesquisa 
DOI: https://doi.org/10.33238/ReBECEM.2020.v.4.n.4.25344

em Educação em Ciências, v. 20, 157-191, jan./dez. 2020. Disponível em:

<https://doi.org/10.28976/1984-2686rbpec2020u157191>. Acesso em: 08 de Jul. 2020.

LISBÔA, J. C. F. QNEsc e a Seção Experimentação no Ensino de Química. Química Nova na Escola, São Paulo, SP, v. 32, n. 2, p. 198-202, dez. 2015. Disponível em:

<http://qnesc.sbq.org.br/online/qnesc37_especial_2/16-EEQ-100-15.pdf >. Acesso em: 08 de Jul. 2020.

LOPES, B. E. R.; MACHADO, B. G. Dos Filósofos Gregos à Bohr: Uma Revisão Histórica sobre a Evolução dos Modelos Atômicos. Revista Ifes Ciência, Vitória, ES, v. 4, n. 2, p. 122139, 2018. Disponível em: 〈https://ojs2.ifes.edu.br/index.php/ric/article/view/1052/701〉. Acesso em: 08 de Jul. 2020.

MACHADO, A. H. Aula de química: discurso e conhecimento. 2ª ed. Ijuí, RS: Ed. Unijuí, 2004.

MARCELINO, V. S.; LINHARES, M. P. OLIVEIRA, F. J. L. O Ensino de Química praticado em Escolas Estaduais de um Município do Estado do Rio de Janeiro/Brasil pela ótica de seus Professores. In: IX CONGRESO INTERNACIONAL SOBRE INVESTIGACIÓN EN DIDÁCTICA DE LAS CIENCIAS, 2013, Girona. Anais..., Girona: 2013. p. 1023-1027.

MARTORANO, S. A. de A.; MARCONDES, M. E. R. Investigando as ideias e dificuldades dos professores de química do ensino médio na abordagem da história da química. História da Ciência e Ensino: construindo interfaces, v. 6, p. 16-31, 2012. Disponível em: <http://ken.pucsp.br/hcensino/article/view/11463/9437>. Acesso em: 08 de Jul. 2020.

MATTHEWS, M. R. History, Philosophy and Science Teaching: what can be done in an undergraduate course? Studies in Philosophy and Education, Dordrecht, Holanda, n. 10, p. 93-97, 1990. Disponível em: <https://link.springer.com/article/10.1007/BF00367690>. Acesso em: 08 de Jul. 2020.

MELO, M. M. R.; LUCA, A. G. Experiências de Estágio Supervisionado Obrigatório Realizado no Curso de Licenciatura em Química do Instituto Federal Catarinense - Campus Araquari. Revista Brasileira da Educação Profissional e Tecnológica, v. 1, n. 18, p. 1-22, 2020. Disponível em: <http://www2.ifrn.edu.br/ojs/index.php/RBEPT/article/view/7502/pdf >. Acesso em: 08 de Jul. 2020.

MORTIMER, E. F.; MACHADO, A. H. M.; ROMANELLI, L. I. A proposta curricular de Química do Estado de Minas Gerais: fundamentos e pressupostos., São Paulo, SP, v. 23, n. 2, p. 273-283, 2000. Disponível em: < https://www.scielo.br/pdf/qn/v23n2/2131.pdf>. Acesso em: 12 de nov. 2020.

MOREIRA, M. A. Aprendizagem Significativa: um conceito subjacente. Aprendizagem Significativa em Revista, Porto Alegre, RS, v. 1, n. 3, p. 25-46, 2011. Disponível em: <http://www.if.ufrgs.br/asr/artigos/Artigo_ID16/v1_n3_a2011.pdf >. Acesso em: 08 de Jul. 2020 . 
NASCIMENTO, T. E.; COUTINHO, C. Metodologias ativas de aprendizagem e o ensino de Ciências. Multiciência Online, p. 134-153, 2016. Disponível em: $<$ http://urisantiago.br/multicienciaonline/adm/upload/v2/n3/7a8f7a1e21d0610001959f0863ce52 d2.pdf >. Acesso em: 08 de Jul. 2020.

NEVES, J. L. Pesquisa Qualitativa - Características, Usos e Possibilidades. Caderno de Pesquisas em Administração, São Paulo, SP, v. 1, n. 3, p. 1-5, 1996.

NICOLA, J. A.; PANIZ, C. M. A importância da utilização de diferentes recursos didáticos no Ensino de Biologia. Infor, Inovação e Formação. Revista do Núcleo de Educação a Distância da Unesp, São Paulo, SP, v. 2, n. 1, p. 355-381, 2016. Disponível em: <https://ojs.ead.unesp.br/index.php/nead/article/view/InFor2120167/pdf>. Acesso em: 08 de Jul. 2020.

NICOLAY, D. A. A noção de infância na Didática Magna de Comenius. Educação Unisinos, São Leopoldo, RS, v. 15, n. 1, jan.-abr. 2011. Disponível em: <https://www.redalyc.org/pdf/4496/449644454002.pdf〉. Acesso em: 08 de Jul. 2020.

OKI, M. da C. M.; MORADILLO, E. F. O ensino de história da química: contribuindo para a compreensão da natureza da ciência. Ciência \& Educação (Bauru), Bauru, SP, v. 14, n. 1, p. 67-88, 2008. Disponível em: 〈https://www.scielo.br/pdf/ciedu/v14n1/05.pdf >. Acesso em: 08 de Jul. 2020.

OLIVEIRA, J. R. S. A Perspectiva Sócio-histórica de Vygotsky e suas Relações com a Prática da Experimentação no Ensino de Química. Alexandria Revista de Educação em Ciência e Tecnologia, v. 3, n. 3, p. 25-45, nov. 2010b. Disponível em: <https://dialnet.unirioja.es/servlet/articulo?codigo=6170770>. Acesso em: 08 de Jul. 2020.

OLIVEIRA, J. R. S. Contribuições e Abordagens das Atividades Experimentais no Ensino de Ciências: Reunindo Elementos para a Prática Docente. Acta Scientiae - Revista de Ensino de Ciências e Matemática, v. 12, n. 1, p. 139-153, jan./jun. 2010c. Disponível em: <http://www.periodicos.ulbra.br/index.php/acta/article/view/31/28>. Acesso em: 08 de Jul. 2020 .

OLIVEIRA, R. J. O. Ensino das Ciências e a Ética na Escola: Interfaces Possíveis. Química Nova na Escola, São Paulo, SP, v. 32, n. 4, p. 227-232, nov. 2010a. Disponível em: <http://qnesc.sbq.org.br/online/qnesc32_4/04-EA0310.pdf>. Acesso em: 08 de Jul. 2020.

PASCHOARELLI, L. C; MEDOLA, F. O; BONFIM, G. H. C. Características Qualitativas, Quantitativas e Quali-quantitativas de Abordagens Científicas: estudos de caso na subárea do Design Ergonômico. Revista de Design, Tecnologia e Sociedade, v. 2, n. 1, p. 65-78, 2015. Disponível em: <http://periodicos.unb.br/index.php/design-tecnologiasociedade/article/download/15699/14030>. Acesso em: 08 de Jul. 2020. 
DOI: https://doi.org/10.33238/ReBECEM.2020.v.4.n.4.25344

PAZINATO, M. S.; BRAIBANTE, M. E. F. Oficina Temática Composição Química dos Alimentos: Uma Possibilidade para o Ensino de Química. Química Nova na Escola, São Paulo, SP, v. 36, n. 4, p. 289-296, nov. 2014. Disponível em:

<http://qnesc.sbq.org.br/online/prelo/RSA-133-12.pdf〉. Acesso em: 08 de Jul. 2020.

PEREIRA, L. F. O Desaparecimento da Infância. Nuances: estudos sobre Educação, Presidente Prudente, SP, v. 18, n. 19, p. 148-152, jan./abr. 2011. Disponível em: <https://revista.fct.unesp.br/index.php/Nuances/article/viewFile/353/388>. Acesso em: 08 de Jul. 2020.

POPPER, K. R. Conhecimento objetivo: uma abordagem evolucionária. São Paulo, SP: Itatiaia: EDUSP, 1975.

PRADO, L.; CARNEIRO, M. C. O episódio histórico das teorias do flogisto e calórico: criando interfaces entre a História e Filosofia da Ciência e o Ensino de Química na busca pela humanização do trabalho científico. História da Ciência e Ensino, v. 18, p. 153-180, 2018. Disponível em: <https://doi.org/10.23925/2178-2911.2018v18p153-180〉. Acesso em: 08 de Jul. 2020.

RAMPAZZO, L. Metodologia científica [para alunos dos cursos de graduação e pósgraduação]. $4^{\text {a }}$ ed. São Paulo, SP: Loyola, 2009.

ROSA, G. P.; DEPS, V. L. Desatenção do Aluno e Estratégias de Aprendizagem no Contexto Escolar. Revista Científica Interdisciplinar, v. 2, n. 4, p. 247-260, out./dez. 2015. Disponível em: <http://dx.doi.org/10.17115/2358-8411/v2n4a22〉. Acesso em: 08 de Jul. 2020.

ROSITO, B. A. O ensino de ciências e a experimentação. In: MORAES, R e or. Construtivismo e ensino de ciências reflexões epistemológicas e metodológicas. $2^{\mathrm{a}}$ ed. Porto Alegre, RS: EDIPUCRS. 2003, p. 195-208.

SANTOS, W. L.P.; SCHNETZLER, R. P. Educação em química: Compromisso com a cidadania. $4^{\text {a }}$ ed. Ijuí, RS: Ed. Unijuí, 2014.

SILVA, S. T. de S.; TEIXEIRA, R. R. de S.; CARDOSO, R. H. F.; CARVALHO, R. C. S.; SANTOS, J. V. da S; VELOSO, V. D. de A. Reflexões sobre o Ensino de Química e a Confecção de Modelos Atômicos com Matérias Reaproveitáveis como Prática Pedagógica. Revista Destaques Acadêmicos, Lajeado, RS, v. 11, n. 4, p. 326-341, 2019. Disponível em: <http://www.univates.br/revistas/index.php/destaques/article/download/2414/1611>. Acesso em: 08 de Jul. 2020.

SILVEIRA, F. L. A Filosofia de Karl Popper e suas Implicações no Ensino de Ciências. Caderno Catarinense de Ensino de Física, Florianópolis, SC, v. 6, n. 2, p. 148-162, 1989.

SOUZA, K. A. de O. NETO-ALBUQUERQUE, O. de L.; SILVA, W. S.; SILVA, A. A.; HARAGUCHI, S. K. "Dominó geométrico": Uma Ferramenta Lúdica para o Ensino de Química 
DOI: https://doi.org/10.33238/ReBECEM.2020.v.4.n.4.25344

sobre Geometria dos pares de elétrons e Geometria Molecular. Scientia Naturalis, Rio Branco, AC, v. 2, n.1, p. 293-311, 2020. Disponível em:

<https://periodicos.ufac.br/index.php/SciNat/article/view/3537>. Acesso em: 08 de Jul. 2020.

SOUZA, S. E. O uso de recursos didáticos no ensino escolar. In: I ENCONTRO DE PESQUISA EM EDUCAÇÃO, IV JORNADA DE PRÁTICA DE ENSINO, XIII SEMANA DE PEDAGOGIA DA UEM, Anais..., Maringá, PR: Arq. Mudi. Periódicos, 2007. p. 110-114.

STRATHERN, P. O sonho de Mendeleiev: A verdadeira História da Química. Tradução, Maria Luiza de A. Borges. Rio de Janeiro, RJ: Zahar, 2002.

THOFEHRN, M. B.; LEOPARDI, M. T. Construtivismo sócio-histórico de Vygostky e a enfermagem. Revista Brasileira de Enfermagem, Brasília, DF, v. 59, n. 5, set./oct. 2006. Disponível em: <https://doi.org/10.1590/S0034-71672006000500019>. Acesso em: 08 de Jul. 2020.

Recebido em: 08 de julho de 2020

Aceito em: 12 de novembro de 2020 